
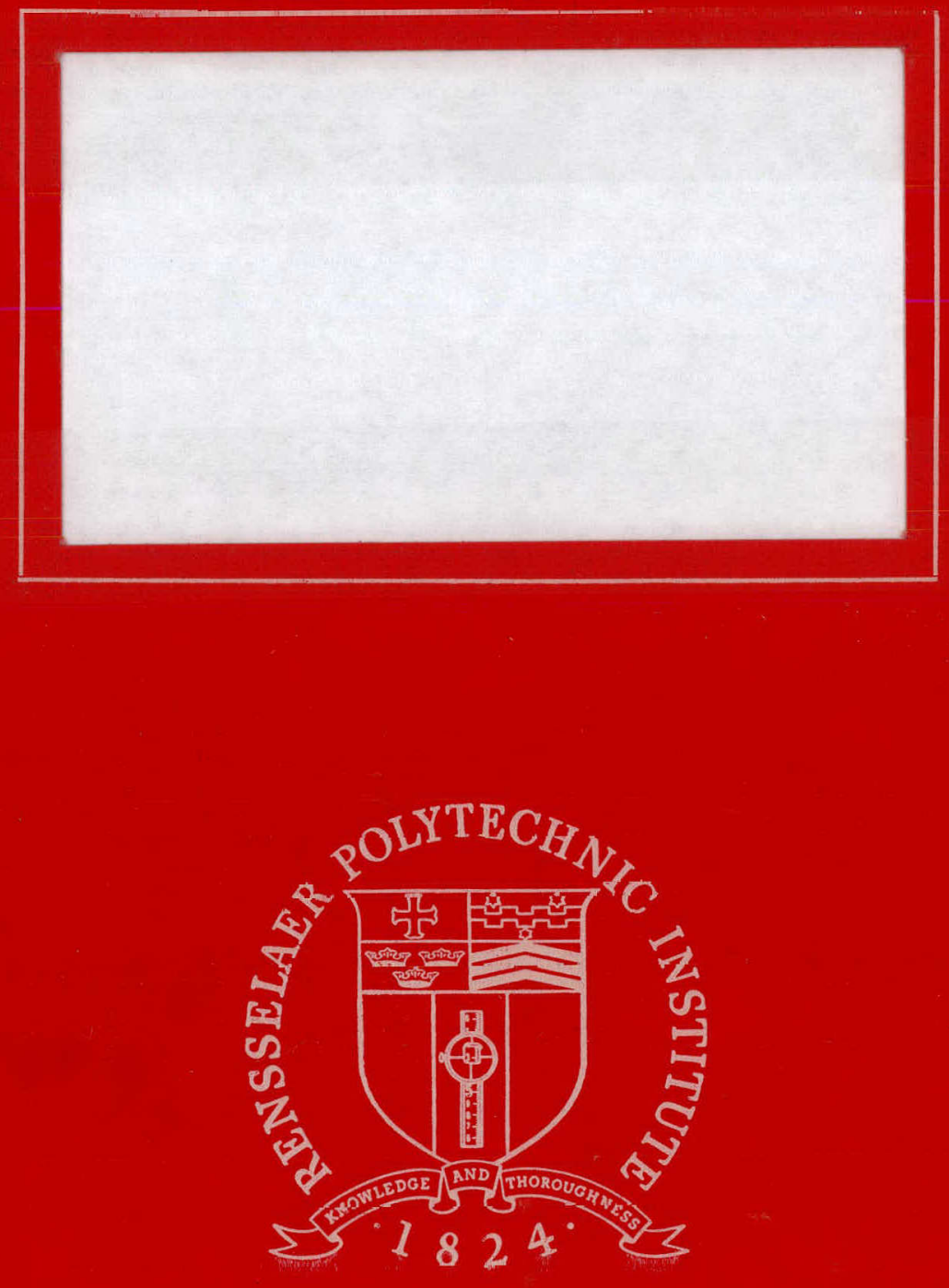

\title{
Rensselaer Polytechnic Institute
}

Troy, New York 12181 


\section{DISCLAIMER}

This report was prepared as an account of work sponsored by an agency of the United States Government. Neither the United States Government nor any agency Thereof, nor any of their employees, makes any warranty, express or implied, or assumes any legal liability or responsibility for the accuracy, completeness, or usefulness of any information, apparatus, product, or process disclosed, or represents that its use would not infringe privately owned rights. Reference herein to any specific commercial product, process, or service by trade name, trademark, manufacturer, or otherwise does not necessarily constitute or imply its endorsement, recommendation, or favoring by the United States Government or any agency thereof. The views and opinions of authors expressed herein do not necessarily state or reflect those of the United States Government or any agency thereof. 


\section{DISCLAIMER}

Portions of this document may be illegible in electronic image products. Images are produced from the best available original document. 


\section{LINEAR ACCELERATOR PROJECT}

AEC Contract No. AT(11-1)-3058

PROGRESS REPORT

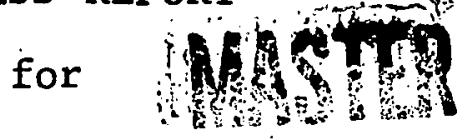

October 1, 1971 - December 31, 1971

LINEAR ACCELERATOR PROJECT

Rensselaer Polytechnic Institute Troy, New York
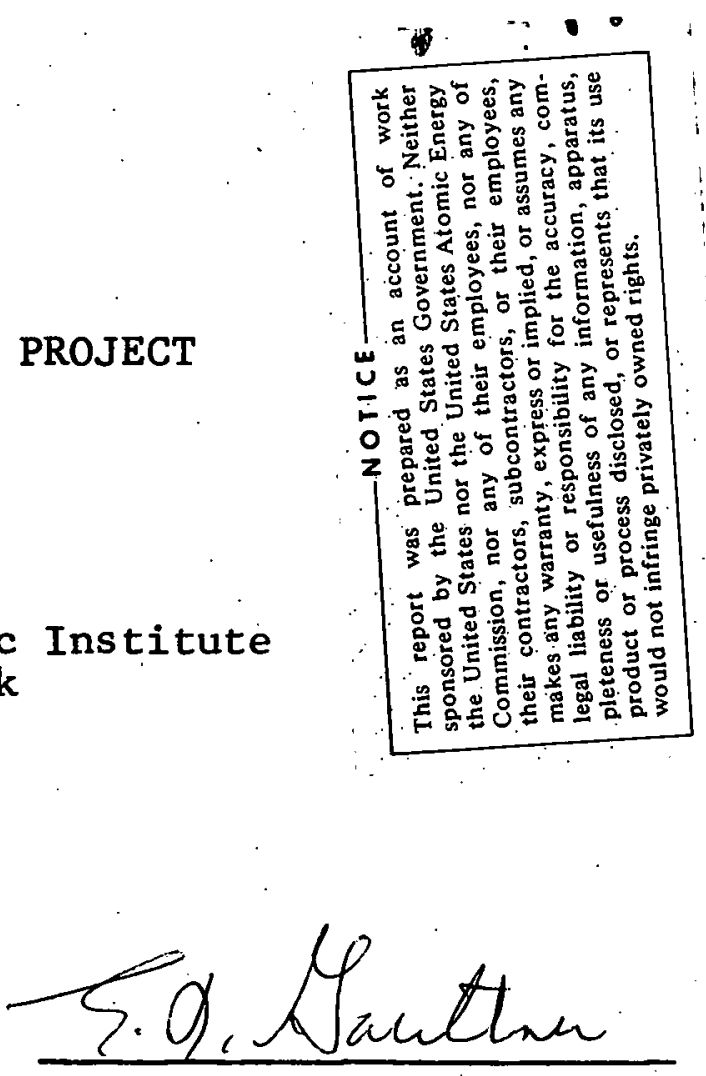

Erwin R. Gaerttner

Project Director 
TABLE OF CONTENTS

Page

NEUTRON CROSS SECTIONS .......................

THE IRON MINIMUM AT $24.3 \mathrm{KEV} \mathrm{-} \mathrm{R.} \mathrm{C.} \mathrm{Block,} \mathrm{K.} \mathrm{Alfieri}$ and $\mathrm{P} . \mathrm{J}$. Turinsky......................

Figures..........................

AREA ANALYSIS OF IRON TOTAL CROSS-SECTION MINIMA K. Alfieri and P. J. Turinsky.................

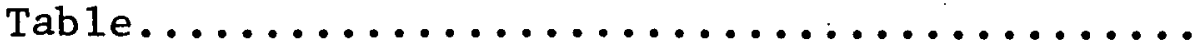

RESONANCE FILTERED NEUTRON BEAMS - A NEW APPROACH TO PRECISION TIME-OF-FLIGHT CROSS-SECTION MEASUREMENTS R. C. Block and R.W. Hockenbury ...............

NEUTRON CAPTURE MEASUREMENTS ON ${ }^{54} \mathrm{Fe},{ }^{58} \mathrm{Fe},{ }^{61_{\mathrm{Ni}} \text { AND }}$ ${ }^{64} \mathrm{Ni}$ - R. W. Hockenbury, N. N. Kaushal, B. Ward and R. C. Block.............................

KEV SUB-THRESHOLD FISSION IN ${ }^{240} \mathrm{Pu}-\mathrm{R}$. W. Hockenbury

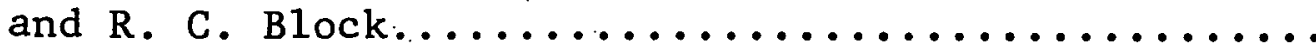

KEV NEUTRON CROSS SECTIONS OF ${ }^{242} \mathrm{Pu}-\mathrm{R}$. W. Hockenbury and $\mathrm{R} . \mathrm{C}$. Block.........................

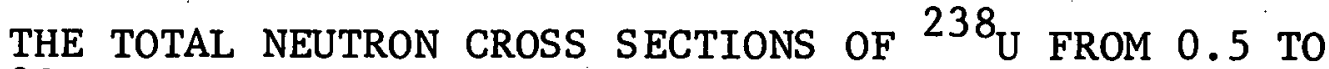
$30 \mathrm{MEV}$ - S. H. Hayes, P. Stoler, J. M. Clement and C. A. Goulding..........................

Figures.........................

CORRELATIONS BETWEEN NEUTRON AND RADIATIVE WIDTHS M. Lubert, R. C. Block and N. C. Francis ...........

KEV NEUTRON ELASTIC SCATTERING CROSS SECTION IN IRON R. Zuhr, Z. Bell and K. Min.................

AVERAGE NEUTRON TRANSMISSION AND SELF-INDICATION RATIO MEASUREMENTS FOR DEPLETED URANIUM IN THE UNRESOLVED RESONANCE REGION - T. Y. Byoun and R. C. Block......

Figures........................... 
Page

REACTOR PHYSICS AND ENGINEERING - EXPERIMENTAL......... 36

ANALYSIS OF FAST NEUTRON SPECTRA IN BULK MEDIA AND

EVALUATION OF DATA FILES - E. R. Gaerttner,

M. W. Golay, N. N. Kausha1, B. K. Malaviya and

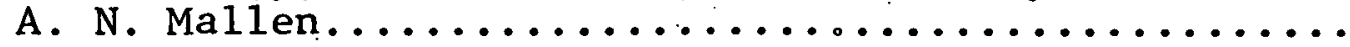

FAST NEUTRON TRANSPORT IN SODIUM - MEASUREMENT AND

ANALYSIS - N. N. Kausha1, B. K. Malaviya, A. N. Mallen

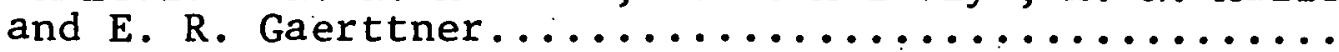

FAST NEUTRON SPECTRA IN TWO-REGION SYSTEMS -

D. C. Gibbs, B. K. Malaviya, N. N. Kaushal and

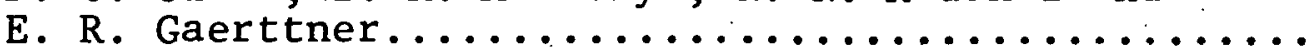

Figure.......................... 41

REACTOR PHYSICS AND ENGINEERING - THEORETICAL ......... 42

REACTOR THEORY AND ANALYSIS - M. Becker, G. Eptstein,

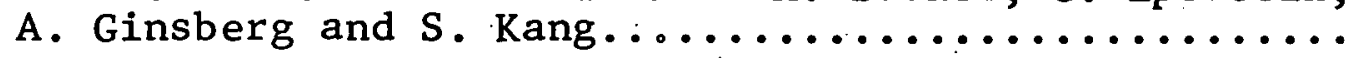

CALCULATION OF EXPERIMENTAL RESOLUTION FUNCTION -

K. Alfieri and P. J. Turinsky................. 46

Figure.......................... 47

COMPUTER DEVELOPMENT $\ldots \ldots \ldots \ldots \ldots \ldots \ldots \ldots \ldots \ldots \ldots \ldots \ldots \ldots$

FOUR YEARS OF REMOTE BATCH OPERATION FROM THE

RENSSELAER LINAC TO THE COURANT INSTITUTE CDC-6600 -

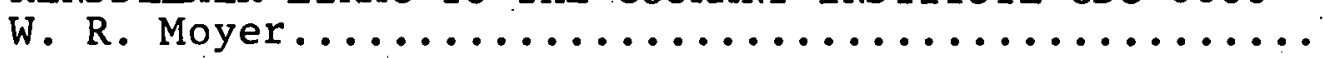


NEUTRON CROSS SECTIONS 
THE IRON MINIMUM AT $24.3 \mathrm{KEV}$

R. C. Block, K. Alfieri ${ }^{*}$ and P. J. Turinsky

A measurement of the total cross section of type c1018 steel was reported in an earlier Progress Report. 1 This steel was part of the iron assembly used in the Fast spectra program ${ }^{2}$ and it had a nominal iron purity of $99.05 \%$. The total cross section of this stepl is plotted in the upper portion of Fig. 1, and a minimum cross section of $0.50 \pm 0.03$ barn was reported for this material. (The data in Fig. 1 have been shifted by $1 / 32 \mathrm{ksec}$ in time-of-flight relative to the data presented in Ref. 1.) Perey ${ }^{3}$ pointed out that the bump at about $23.7 \mathrm{keV}$ was probably due to the $\sim 0.7 \% \mathrm{Mn}$ content of the steel, and an additional low energy transmission measurement was carried out to determine the exact Mn content. This measurement was completed in December, and by comparing the observed area of the Mn resonance at $330 \mathrm{eV}$ with the known Mn resonance parameters, 4 we obtained a Mn content by weight of $(0.82 \pm 0.05) \%$ in this batch of $\mathrm{Cl018}$ steel. This value is $15 \%$ greater than the nominal $0.71 \%$ previous $1 y$ assumed for this steel, but is within the range of $\mathrm{Mn}$ contents reported by manufacturers for this type steel.

A new transmission measurement was more recently carried out in which very pure ( $>99.9 \%$ ) Armco iron was used both as the 14-inch filter and as the 5.95-inch transmission sample. In addition, a measurement with a pure Mn sample was interspersed with the iron measurement to determine both our resolution-broadened Mn cross section and the relative location of the iron minima and the Mn peak.

The total cross section for the Armco iron is plotted in Fig. 2, and we now observe both a deeper minimum of $0.41 \pm 0.03$ barn and a wider minimum. We have also corrected the steel 01018 cross section for the $0.82 \% \mathrm{Mn}$ content (determined by us) and the $0.17 \% \mathrm{C}, 0.031 \% \mathrm{Cr}, 0.02 \% \mathrm{~S}$, and $0.01 \% \mathrm{P}$ content (reported by the manufacturer). This corrected iron cross section is plotted

ॠBased in part on the Master's Engineering Project of $\mathrm{K}$. Alfieri. 
in the lower portion of Fig. 1. The shaded region essentially represents the range of uncertainty in the amount of $\mathrm{Mn}$ and $\mathrm{C}$ in the c1018 steel. This corrected iron cross section has a minimum of $0.40 \pm 0.03$ barn, and it is in excellent agreement both in shape and in magnitude with the pure Armco iron cross section of Fig. 1.

Our total cross-section results for iron, both for the Armco and the corrected $\mathrm{Cl018}$ steel, are in excellent agreement with the recent measurements at oak Ridge. ${ }^{5}$ However, our minimum cross section of 0.41 barn is in disagreement with the 0.51 barn result reported by the Columbia group.

The effect of the $0.82 \% \mathrm{Mn}$ in this batch of $\mathrm{C} 1018$ steel is seen to be quite dramatic in the upper curve of Fig. 1. Not only does the Mn increase the minimum cross section by about $15 \%$ from about 0.49 to 0.50 barn, but it also fills in part of the width of this valley in the iron cross section. This combination of raising the minimum and decreasing the width of the iron window has a great effect upon the transport of neutrons in iron assemblies. This explains the correct interpretation by the Fast Spectra group that for their C1018 steel assembly they need a minimum cross section slightly in excess of 0.50 barn to fit their data.

The experimental results are summarized as follows:

Minimum Fe Cross Section:

Energy of Fe Minimum:

Energy of Mn Resonance Peak:

Difference in Energy Between Fe

Minimum and Mn Resonance Peak:
$0.41+0.02$ barn

$24.3 \mp 0.1 \mathrm{keV}$

$23.65 \mp 0.05 \mathrm{keV}$

$0.65 \pm 0.11 \mathrm{keV}$

REFERENCES :

1. Linear Accelerator Project Progress Report, Apri1 - June 1971, RPI -328-226.

2. B. K. Malaviya et a1., accepted for publication in Nucl. Sci. Eng. (1972).

3. F. Perey, private communication.

4. BNL-325, 2nd ed., Supplement No. 2, Vol. II A (1966).

5. F. Perey and J. A. Harvey, private communication.

6. F. Rahn, H. Camarda, G. Hacken, W. W. Havens, Jr ., H. Liou, J. Rainwater, M. Slagowitz and S. Wynchank, accepted for pub1ication in Nucl. Sci. Eng. (1972). 


\section{FIGURE CAPTIONS}

Fig. 1 The Upper Set of Points is the Total Neutron Cross Section near $24.3 \mathrm{keV}$ of the $\mathrm{C} 1018$ Steel used for the Fast Spectrum Measurements: ${ }^{2}$ The lower set of points has been corrected for impurities and represents the pure iron cross section. The shaded area surrounding the lower curve represents the range of uncertainty in the impurity corrections. The curves through the points are eyeball fits and the error bars represent standard deviations due to counting statistics.

Fig. 2. The Total Neutron Cross Section of Armco Iron ( $>99.9 \%$ iron) near the $24.3 \mathrm{keV}$ minimum. The curve through the points is an eyeball fit and the error bars represent standard deviations due to counting statistics. 


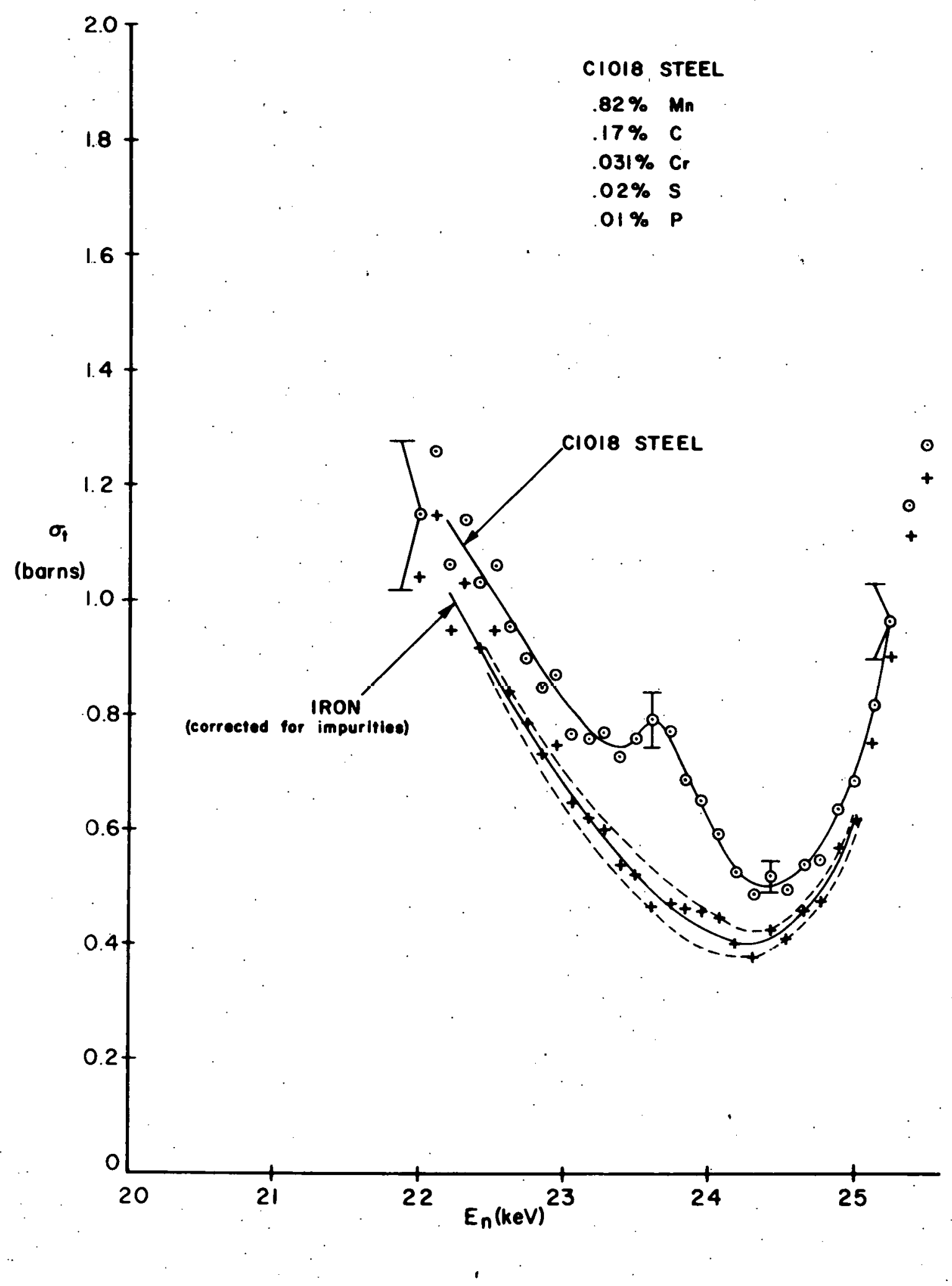

Figure 1 


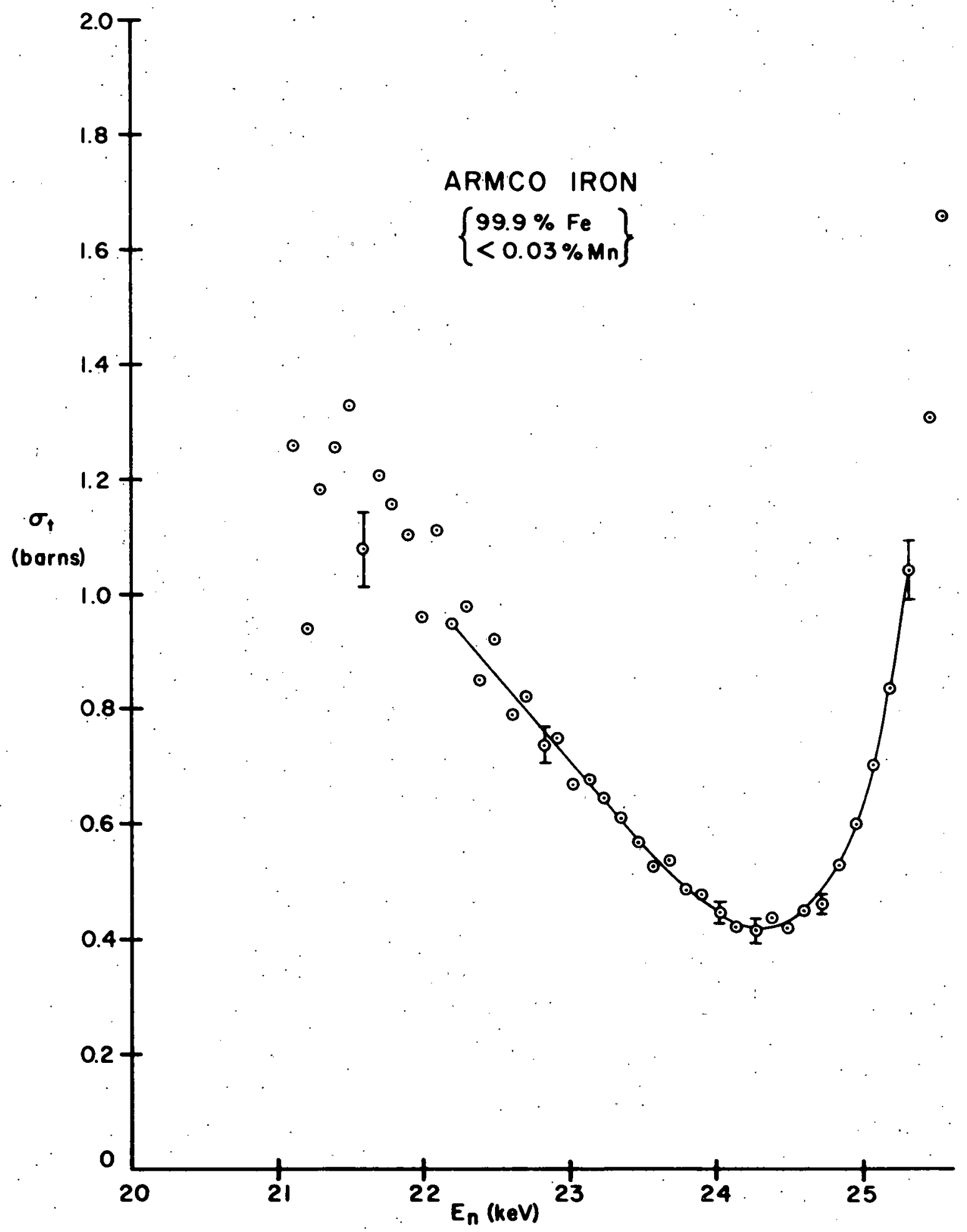

Figure 2 
AREA ANALYSIS OF IRON TOTAL CROSS-SECTION MINIMA

$$
\text { K. Alfieri }{ }^{*} \text { and P. J. Turinsky }
$$

The RPI LINAC has been employed to remeasure the minima of the total neutron cross section of iron. Thick sample (14 and 20 inches) time-of-flight ( $\mathrm{T} \emptyset \mathrm{F})$ transmission experiments on very high purity armco iron ( $>99.9 \% \mathrm{Fe},<0.03 \% \mathrm{Mn}$ ) have been performed. Point cross-section behavior extracted from this experiment is presented elsewhere in this report, with the present paper concerned with area analysis.

We have previously shown ${ }^{1}$ that meaningful comparisons of experimental data and tabulated files can be made for integral properties of the cross-section minima without resolution corrections. Let $C(d, E)$ be the counts recorded for a sample of thickness $d$ in $T \emptyset F$ channel with associated energy $E$. Further, let $E_{1}$ and $E_{2}$ be energies bracketing a maxima in the $C(d, E)$ versus $E$ curve; i.e., minima in the total cross section. As shown previously, the ratio of areas under the $C(d, E)$ curve between $E_{1}$ and $E_{2}$ for two different sample thicknesses is then approximately independent of resolution corrections and given by

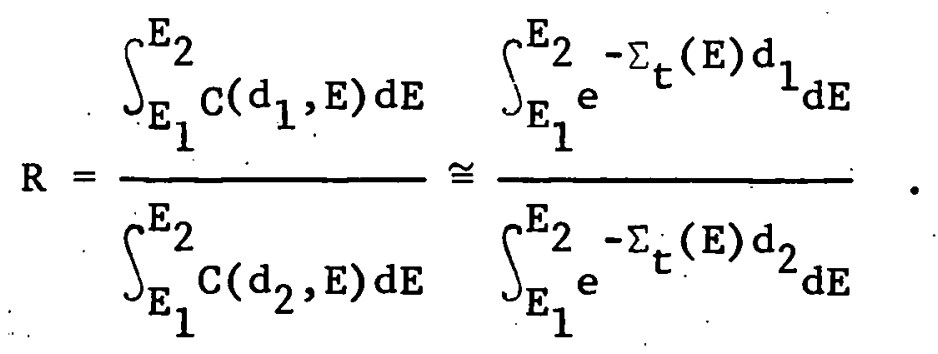

We have compared values of $R$ obtained directly from our experiment, denoted $R_{R P I}$, to those calculated from the RHS of Eq. (1) employing iron total cross sections from files ENDF/B-III (MAT 1124-Preliminary) and Version $19^{2}$, denoted $\mathrm{R}_{\mathrm{T}}$.

In Table 1 are presented results in terms of relative percentage errors, defined by

$$
\varepsilon=\frac{R_{R P I}-R_{T}}{R_{R P I}} \times 100 \%
$$

₹ Based in part on the Master's Engineering Project of $\mathrm{K}$. Alfieri. 
for various energy regions spanning minima. Also indicated are uncertainty limits on $\varepsilon$ due to counting statistics. As stated (for $\mathrm{d}_{1}=14^{\prime \prime}$ and $\mathrm{d}_{2}=20^{\prime \prime}$ ), $\varepsilon>0$ indicates that the data files generally underestimate the experimentally measured minima cross section; whereas, $\epsilon<0$ implies overestimation. As an example, for the $24.3 \mathrm{keV}$ cross-section minima we measure $\sigma_{\min }=0.41 \pm 0.03 \mathrm{~b}$, with $0.285 \mathrm{~b}$ and $0.486 \mathrm{~b}$ being the respectively stated values for $\sigma_{\text {min }}$ in files ENDF/B-III and Version 19. Table 1 indeed confirms the under and over estimations. Note that caution should be exercised in employing such a simple interpretation based entirely on $\sigma_{\min }$ since the shape of the cross section obviously enters the integral in Eq. (1). From Table 1 we conclude that the Version 19 file is superior to the ENDF/B-III file in correctly representing the minima in iron for most of the $20-400 \mathrm{KeV}$ energy range analyzed.

\section{REFERENCES :}

1. Linear Accelerator Project Annual Technical Report, October 1, 1970 - September 30, 1971, 19, C00-3058-1.

2. C. Lubitz, private communication (1971). 
Table 1

Comparison of Experimental and Total Iron Cross Sections from Files ENDF/B-III and Version 19 through Minima by Area Analys is

ENDF/B-III

\begin{tabular}{lr}
$\begin{array}{c}\text { Energy Range } \\
(\mathrm{KeV})\end{array}$ & $\begin{array}{r}\text { Relative Error } \\
(\varepsilon)\end{array}$ \\
\hline $20.2-27.0$ & $13 \pm 1 \%$ \\
$67.9-71.8$ & $12 \pm 12 \%$ \\
$78.8-83.0$ & $-200 \pm 1 \%$ \\
$114.8-130.5$ & $-148 \pm 4 \%$ \\
$132.0-139.6$ & $-57 \pm 1 \%$ \\
$155.2-169.2$ & $-133 \pm 2 \%$ \\
$171.3-187.6$ & $26 \pm 1 \%$ \\
$203.4-224.6$ & $-202 \pm 4 \%$ \\
$231.2-278.1$ & $-112 \pm 4 \%$ \\
$282.7-317.8$ & $-103 \pm 2 \%$ \\
$323.3-387.9$ & $-7 \pm 1 \%$ \\
$419.2-505.2$ & $-33 \pm 4 \%$ \\
$527.9-740.2$ & $-4 \pm 2 \%$ \\
$802.3-1413.2$ & $-6 \pm 5 \%$
\end{tabular}

VERSION 19

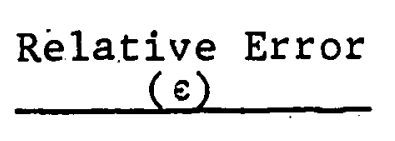

$-6 \pm 1 \%$

$-116 \pm 32 \%$

$-18 \pm 1 \%$

$-16 \pm 2 \%$

$-44 \pm 1 \%$

$-19 \pm 1 \%$

$-13 \pm 2 \%$

$-19 \pm 1 \%$

$-8 \pm 1 \%$

$21 \pm 1 \%$

$4 \pm 1 \%$

Over

over

-

\section{Comparison} with RPI's Cross Sections

Over

Over

Over

Over

Over

Over

Over

Over

Over

Under

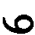

- 


\section{RESONANCE FILTERED NEUTRON BEAMS - A NEW APPROACH TO PRECISION TIME-OF-FLIGHT CROSS-SECTION MEASUREMENTS \\ R. C. Block and R. W. Hockenbury}

The following is an abstract of a paper which has been submitted for presentation at the Washington meeting of the American Physical Society, April 24-27, 1972.

\section{ARS TRACT}

Iron filters varying in thickness from 6 to 20 inches were placed in the $25 \mathrm{~m}$ spectrometer at the RPI LINAC; over ten distinct neutron energy bands (corresponding to cross-section minima) were observed between $24 \mathrm{keV}$ and $1 \mathrm{MeV}$. In particular, the 24 $\mathrm{keV}$ band is $\leadsto 2 \mathrm{keV}$ wide and is separated by $>45 \mathrm{keV}$ from the next nearest band. For transmission measurements the signal-tobackground ratio is $500: 1$, and for capture in ${ }^{238} \mathrm{U}$ this ratio is $5: 1$. In both measurements this background can be measured extremely accurately, permitting high accuracy cross-section determination. The problem of the finite number of resonances sampled in a $2 \mathrm{keV}$ band is the ultimate limitation of this technique in the resonance region (about $\pm 5 \%$ for ${ }^{238} \mathrm{U}$ ). Thus, this filteredbeam measurement must be carried out in conjunction with highresolution white source TOF measurements to pin down fluctuations due to nuclear statistics. 
NEUTRON CAPTURE MEASUREMENTS ON ${ }^{54} \mathrm{Fe},{ }^{58} \mathrm{Fe},{ }^{61_{\mathrm{Ni}} \text { AND }}{ }^{64} \mathrm{Ni}$ R. W. Hockenbury, N. N. Kaushal, B. Ward ${ }^{*}$ and R. C. Block

Time-of-flight capture measurements were made on ${ }^{61} \mathrm{Ni}$ (two samples), ${ }^{64} \mathrm{Ni}$ and ${ }^{54} \mathrm{Fe}$ over the range from $20 \mathrm{eV}$ to about $300 \mathrm{keV}$. The data acquisition program with automated sample cycling was described before. 1

One pulse-height vs time-of-flight measurement was made on ${ }^{54} \mathrm{Fe}$ to obtain the capture detector efficiency.

The eight position sample changer is being modified for faster cycling times.

\section{REFERENCES :}

1. Linear Accelerator Project Annual Technical Report, October 1, 1970 - September 30, 1971, C00-3058-1.

* Based in part on the Master's Engineering Project of B. Ward. 


$$
\begin{aligned}
& \text { KEV SUB-THRESHOLD FISSION IN }{ }^{240} \mathrm{Pu} \\
& \text { R. W. Hockenbury and R. C. Block }
\end{aligned}
$$

The following is an abstract of a paper which has been submitted for presentation at the Washington meeting of the American Physical. Society, April 24-27, 1972.

\section{ABSTRACT}

At least 21 fission groups are observed in the sub-threshold fission cross section of $240 \mathrm{Pu}$ from $750 \mathrm{eV}$ to $30 \mathrm{keV}$. The average level spacing $D_{I I}$ of these fission groups is $710 \pm 60 \mathrm{eV}$ compared to a spacing $\mathrm{D}_{\mathrm{I}}$ of $13.7 \pm 0.5 \mathrm{eV}$ for levels in the first minimum. This level spacing $D_{I I}$ corresponds to an excitation energy of 3.1 $\mathrm{MeV}$, implying that the second minimum proposed by Strutinsky ${ }^{1}$ is about $2.3 \mathrm{MeV}$ above the first minimum in ${ }^{241} \mathrm{Pu}$. Fission widths are obtained for the Class I resonances below $2.5 \mathrm{keV}$ (where the resolution is good). Fission widths for the class II resonances have been obtained up to $10 \mathrm{keV}$ by integrating over the class I resonances in each fission group. The distribution of fission widths over the Class I resonances indicates very weak coupling between Class I and Class II states.

REFERENCE :

1. W. M. Strutinsky, Nuc1. Phys., A95, 420 (1967). 


\section{KEV NEUTRON CROSS SECTIONS OF ${ }^{242} \mathrm{Pu}$ \\ R. W. Hockenbury and R. C. B1ock}

An oxide sample has been converted to a metal foil ${ }^{1}$ for $\mathrm{keV}$ neutron capture, fission and total cross-section experiments. The sample will be doubly encapsulated in A1. Parts of one sample container and a blank have been fabricated. Data reduction codes used for the ${ }^{240} \mathrm{Pu}$ analysis ${ }^{2}$ are being revised for the PDP-15 (with Interactive Display). New bases have been made for the $\mathrm{K} 1328$,photomultiplier tubes of the $1.25 \mathrm{~m}$ capture detector. Bench tests have been made with a new fast overload recovery preamplifier.

\section{REFERENCES :}

1. At Oak Ridge National Laboratory.

2. R. W. Hockenbury, J. D. Boice, W. R. Moyer and R. C. Block, Proc. Third Conf. on Neutron Cross Sections and Technology, Vo1. 2, 721 (1971). 
THE TOTAL NEUTRON CROSS SECTIONS OF ${ }^{238}$ U FROM 0.5 TO $30 \mathrm{MEV}$ S. H. Hayes, ${ }^{*}$ P. Stoler, J. M. Clement and C. A. Goulding

This paper has been submitted for presentation at the Washington meeting of the American Physical. Society, April 24-27, 1972 with the following abstract.

\author{
ABSTRACT \\ TOTAL MEV NEUTRON CROSS SECTION OF ${ }^{238_{U}}$ \\ S. H. Hayes, P. Stoler, J. M. Clement \\ and C. A. Goulding
}

A measurement of the total neutron cross section
of $238 \mathrm{U}$ was made, using the RPI electron LINAC. The operating electron energy was about $60 \mathrm{MeV}$, and the beam burst width was $20 \mathrm{~ns}$. The neutron energies were determined using the time-of-flight technique with a resolution of $.08 \mathrm{~ns} / \mathrm{m}$. The cross section is presented from 0.7 to $30.0 \mathrm{MeV}$. The cross section is smooth in this region, and the averaged data have a statistical precision of $1 \%$. The data reported here have been compared with other recent measurements and the ENDF-B file. There is generally good agreement with a few percent deviations in certain energy regions. In addition, the experimental cross sections were fit using coupled channel code JUPITOR ${ }^{4}$ to obtain optical model and deformation parameters.

Because the uranium and plutonium isotopes are such crucial components of reactor assemblies, one may be led to assume that total neutron cross sections for these isotopes have long been

* Based in part on the Master of Science Thesis of S. H. Hayes. 
precisely measured. However, the data files of the National Neutron Cross Section Center (NNCSC) at Brookhaven National Laboratory, reveal that this is not the case. For example, there have been only two recent measurements of the ${ }^{238} \mathrm{U}$ total neutron cross-section measurements in the MeV range. One is by Smith and Whalen, ${ }^{1}$ which covers the energy range $0.5-1.5 \mathrm{MeV}$, and the other is by Foster and Glasgow, ${ }^{2}$ covering the range from 2.5 to $15 \mathrm{MeV}$. In neither case is the quality of the data as high as can be obtained with current white source techniques. Similar considerations are true for the other fissile isotopes as well. For this reason it is felt that precision measurement of isotopes are warranted.

As of this report we have completed measurements of the total neutron cross sections of ${ }^{238} \mathrm{U}$. A $60 \mathrm{MeV}$ linac electron beam enabled precise measurements to be carried out from 0.5 to $30 \mathrm{MeV}$. The neutron source was made of tungsten and boron carbide. Figure 1 shows a typical neutron spectrum produced by the target. This is uncorrected for detector efficiency. The neutron burst width of $20 \mathrm{nsec}$ and the analysis channel width of $10 \mathrm{nsec}$ limited the resolution at the 250 -meter flight station to $0.08 \mathrm{nsec} / \mathrm{m}$. Only a single detector module with a simple fourfold coincidence requirement on the four phototubes was used, thus simplifying the electronics somewhat. The sample was a depleted $(0.25 \%$ contamination of ${ }^{235} \mathrm{U}$ ) block of ${ }^{238} \mathrm{U}$ with $\mathrm{nl}$ equal to 0.121 atoms/barn. Thin layers of $\mathrm{B}_{4} \mathrm{C}$ and $\mathrm{Cd}$ were used to filter out low energy neutrons. Lead and tantalum filters reduced the gamma flash. A one-half inch diameter brass collimator just upstream of the sample was the final collimating device.

The cross sections obtained will be combined with future runs on ${ }^{238_{U}}$ to decrease the statistical error, and provide a consistency check. The current run appears reliable from several points of view. The background determination was clean, as can be seen in Fig. 2. This figure shows the early data channels for sample-in. The flat region seen in the figure occurs before the first data neutron has had time to arrive at the detector. 
It was accordingly taken as background. This procedure has been used previously with success. ${ }^{3}$ The background varied from $0.6 \%$ to $10 \%$ over the entire energy range and was no more than $2 \%$ over most of the energy range for sample-in. For sample-out it was proportionately smaller. Two checks for internal consistency were made. Data taken early in the run were compared with data taken quite late. There was excellent agreement. Data taken with the computer clock were compared with the data taken with the TAC. Again there was excellent agreement (to within a few tenths percent in all cases).

Figure 3 is a plot of the cross section on a log energy scale. The cross sections displayed have been energy averaged. There is good agreement between the data reported here and the data taken by other experimenters. The Brookhaven library furnished current data on $238_{U}$. As previously mentioned, one set was taken by Smith and Whalen ${ }^{1}$ and covered the energy range from 0.5 to $1.5 \mathrm{MeV}$. The other set was taken by Foster and Glasgow ${ }^{2}$ and covered the energy range from 2.5 to $15 \mathrm{MeV}$. Our data were about $1 \%$ lower than the Smith and whalen data and about $1 \%$ higher than the Foster and Glasgow data. Detailed comparison is shown in Figs. 4 to 6.

REFERENCES :

1. A. B. Smith and D. W. Whalen, private communication to Brookhaven National Laboratory.

2. D. G. Foster and D. W. Glasgow, Phys. Rev., 3, 576 (1971).

3. J. M. Clement, P. Stoler, C. A. Goulding and R. W. Fairchild, Nuc1. Phys. (in press).

4. T. Tamura, Rev. Mod. Phys., 37, 679 (1965). 


\section{FIGURE CAPTIONS}

Fig. I A Typical Spectrum of Neutron Produced by the Conversion Target as seen by the Detector. It is uncorrected for detector efficiency.

Fig. 2 A Portion of the Sample-in Neutron Spectrum, showing the earliest Data Channels. Note the flat time-independent background which supercedes the arrival of the highest energy neutrons.

Fig. 3 The ${ }^{238_{\mathrm{U}}}$ Total Neutron Cross Section from $\mathrm{I}$ to $30 \mathrm{MeV}$. The data has been pre-averaged to improve the statistical precision. Thus, the number of points shown are less than the total number of data channels.

Fig. 4 The ${ }^{238} U$ Total Neutron Cross Section from $0.7-1.0 \mathrm{MeV}$. The solid curve is an "eyeball" fit through the data of Smith and Whalen. 1

Fig. $5{ }^{238} \mathrm{U}$ Total Neutron Cross Section from $1-6 \mathrm{MeV}$ : The solid curve on the left is a fit to the data of Smith and Whalen. The solid curve from $2.5-6 \mathrm{MeV}$ is an "eyeball" fit to the data of Foster and Glasgow. 2

Fig. $6{ }^{238} \mathrm{U}$ Total Neutron Cross section from $6-30 \mathrm{MeV}$. The solid curve is a fit to the data of. Foster and Giasgow. 2 


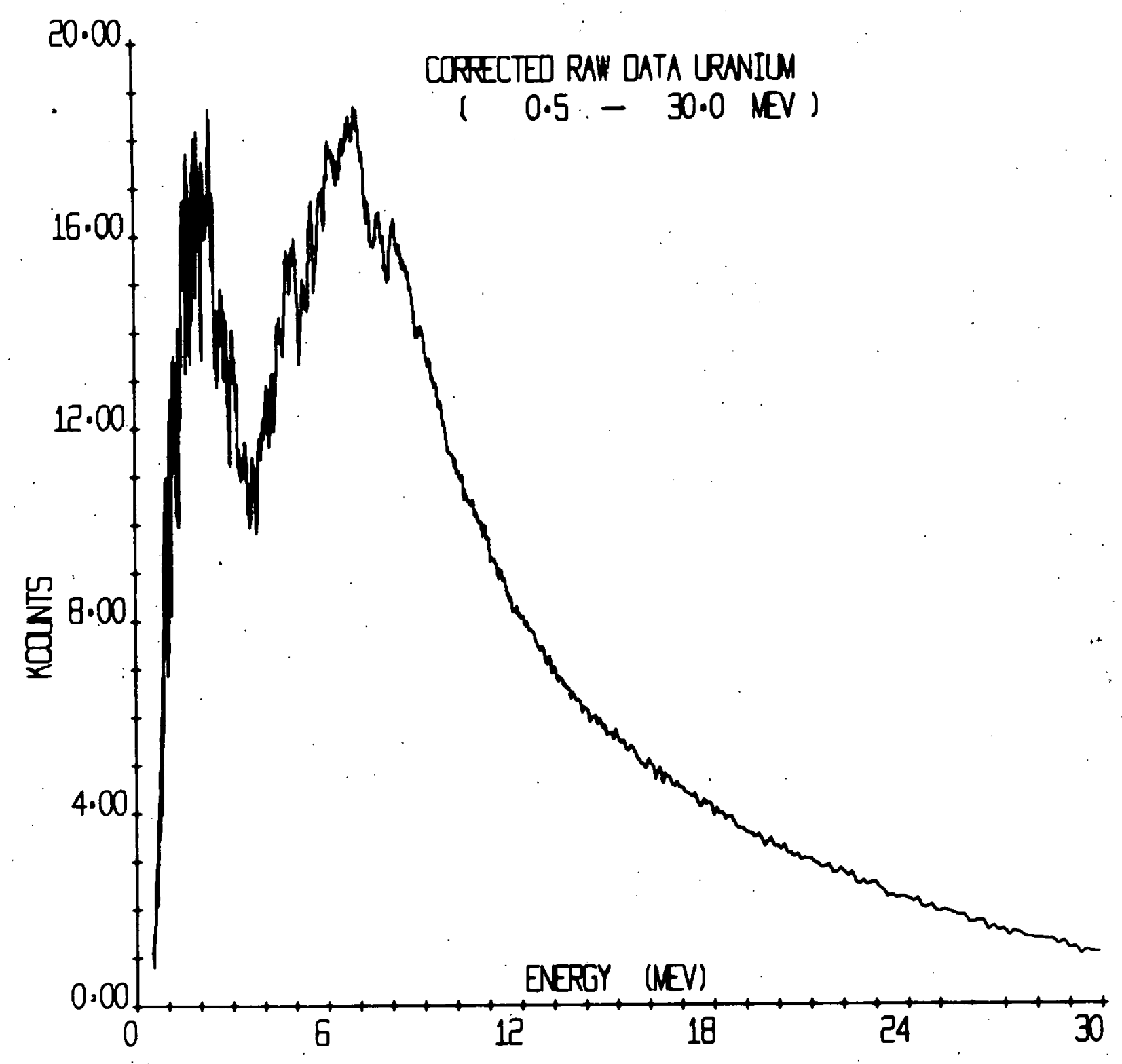

Figure 1 


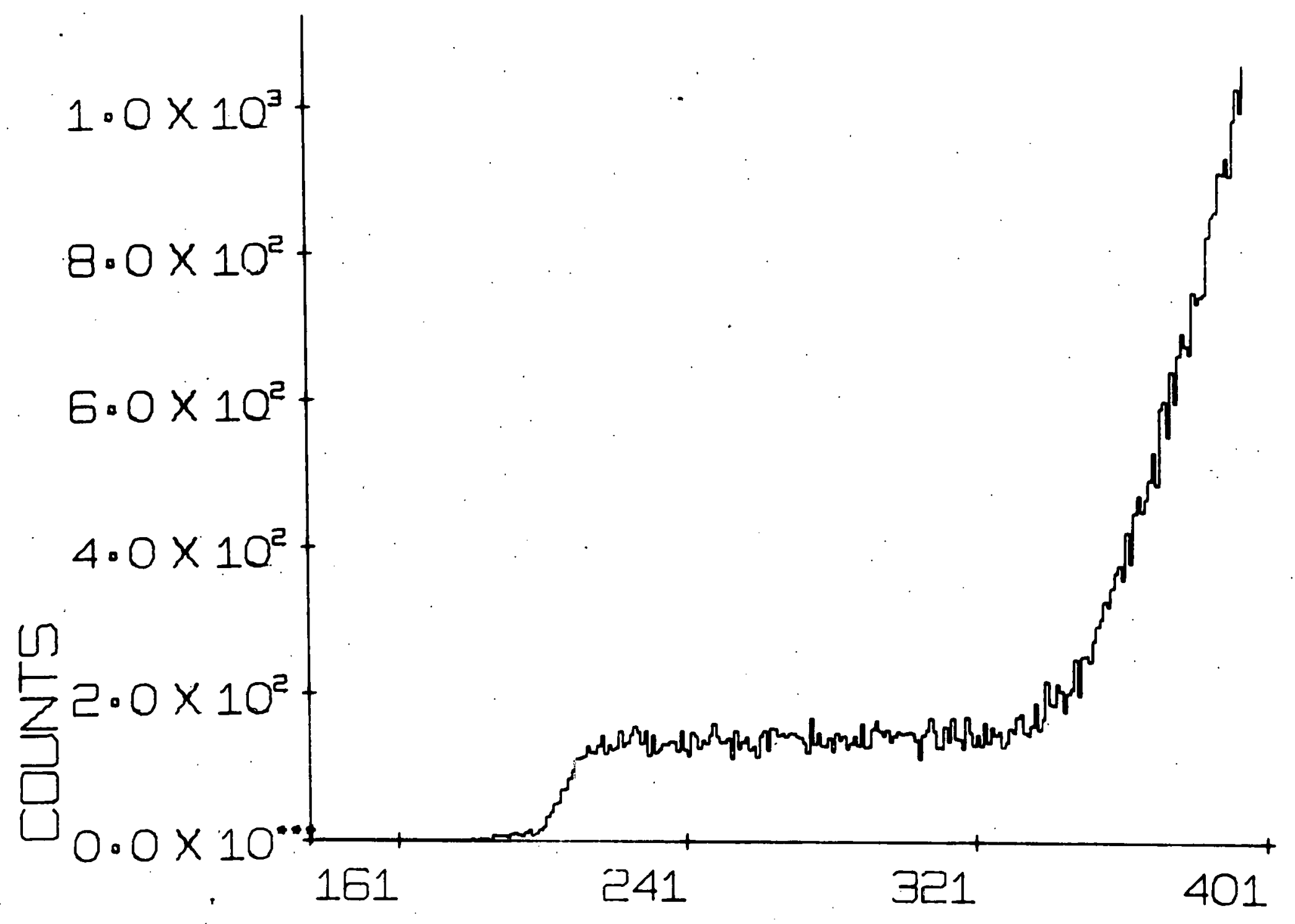

Figure 2 


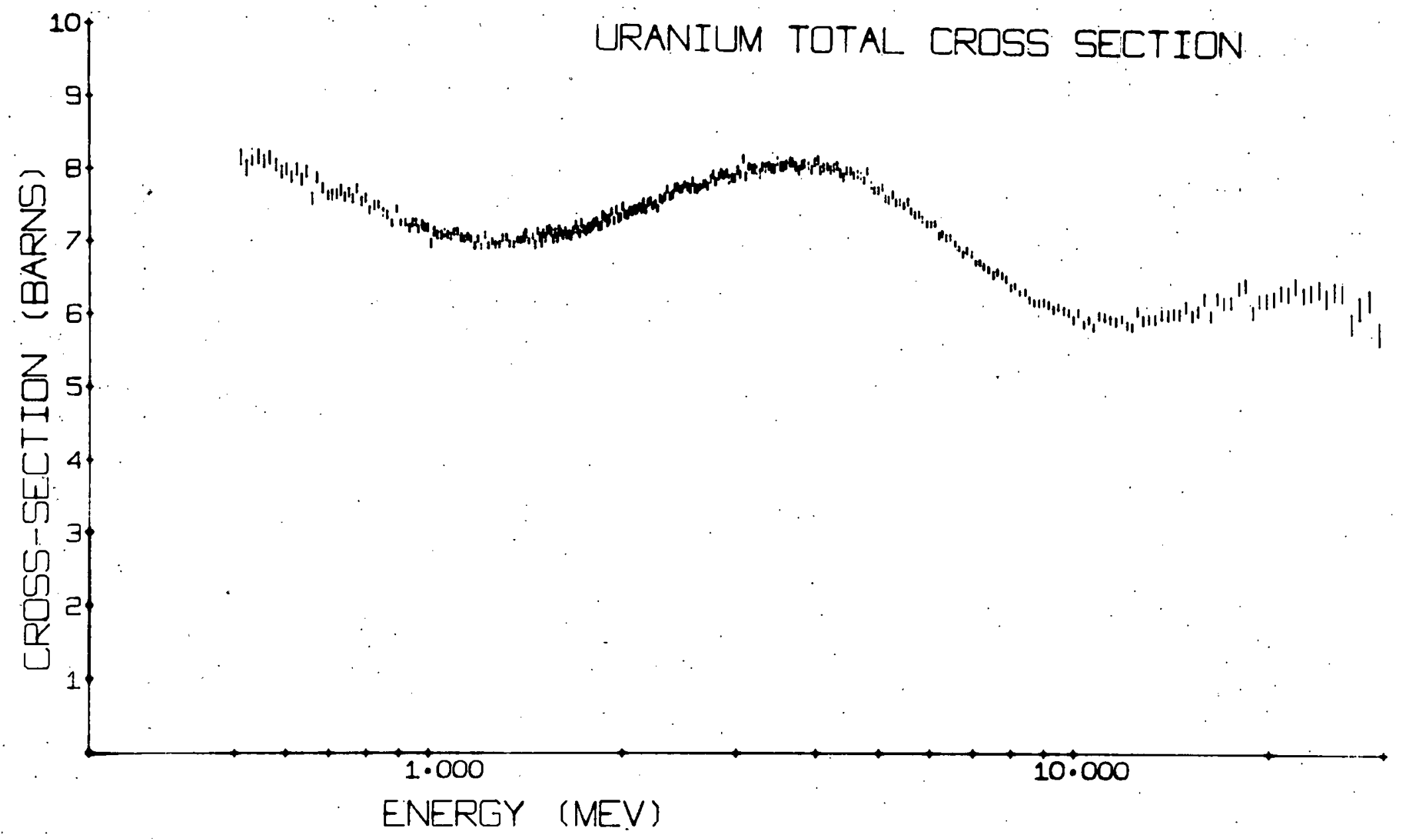

Figure 3 


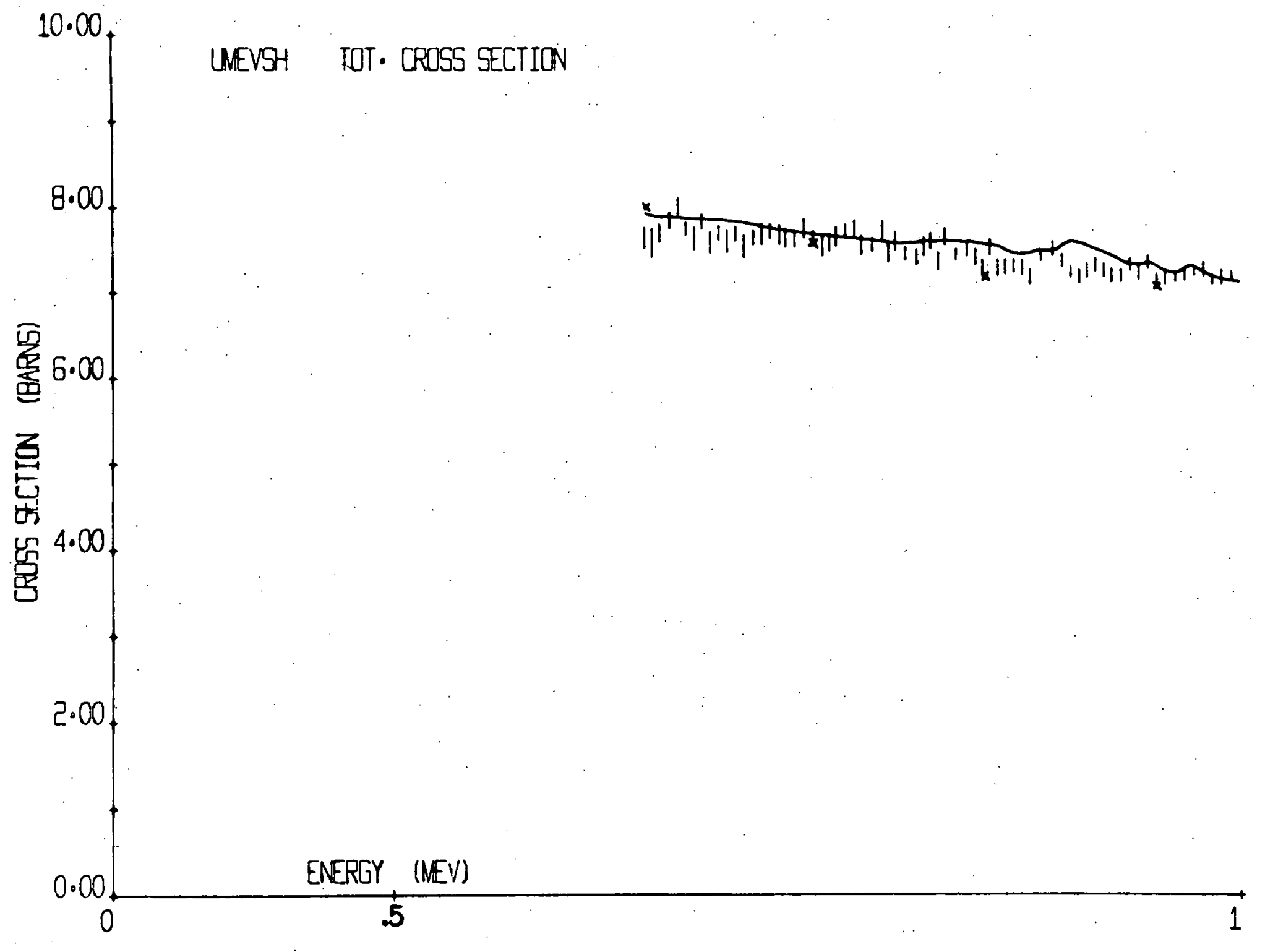

Figure 4 


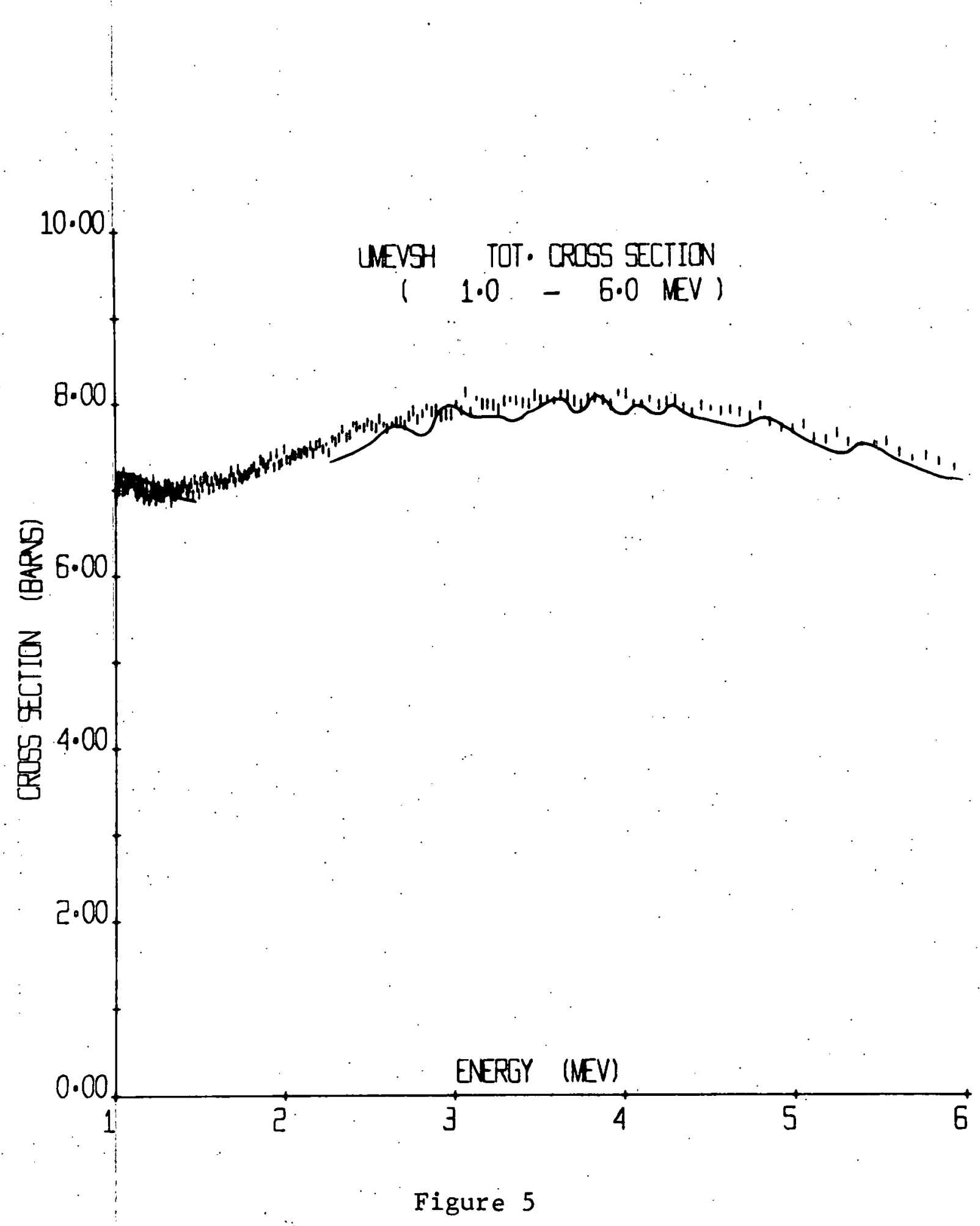




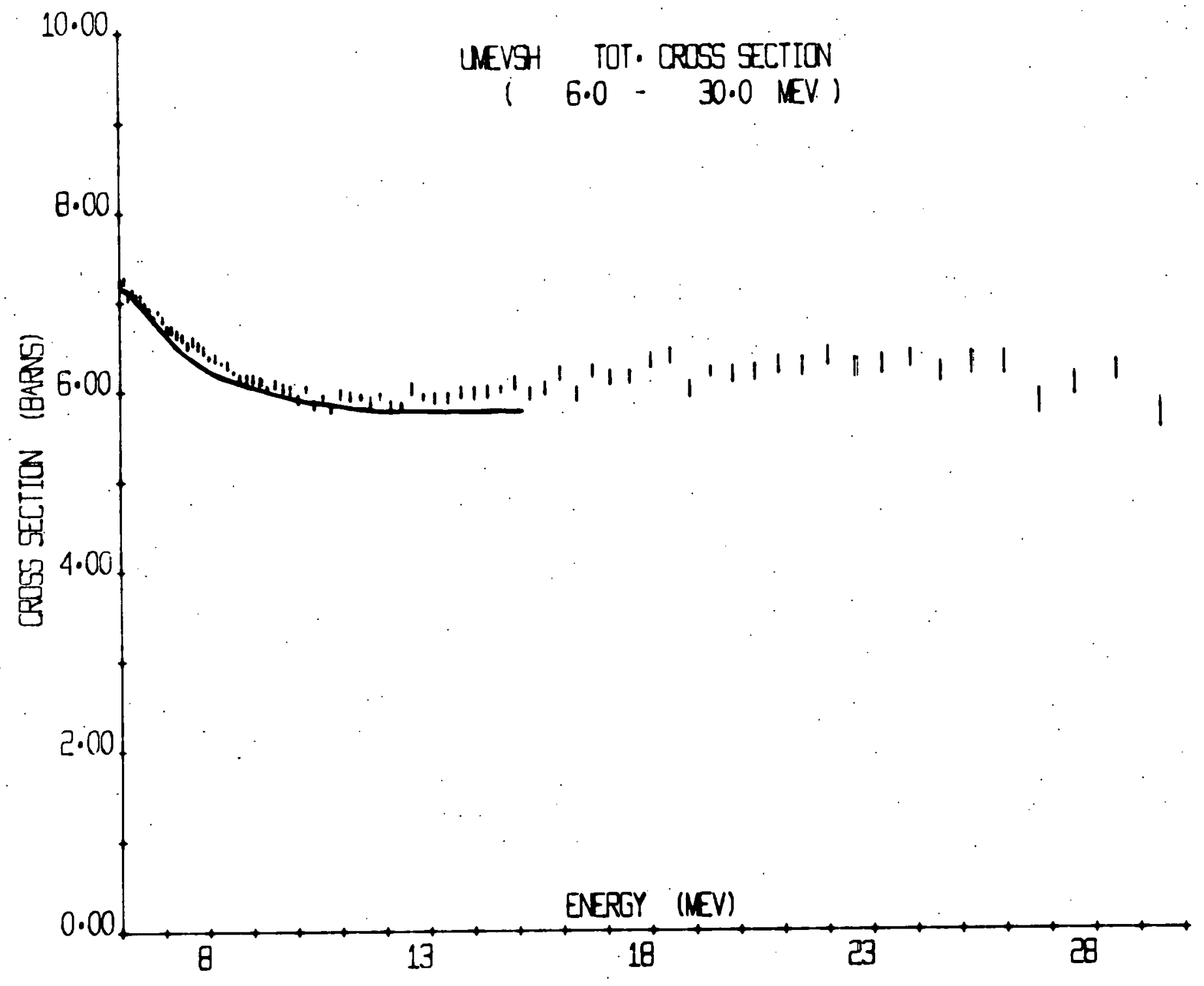

Figure 6 
CORRELATIONS BETWEEN NEUTRON AND RADIATIVE WIDTHS

M. Lubert, ${ }^{*}$ R. C. Block and N. C. Francis

The cross sections for the chromium isotopes measured at the RPI LINAC indicate a positive correlation between the measured neutron and radiation widths. The neutron. widths are normally expected to be distributed as a Chi-square function with one degree of freedom while the radiation widths exhibit Chi-square distribution with $n$ degrees of freedom $\left(n_{050}\right)$. The radiation widths are usually constant over the energy range of interest. It has been shown ${ }^{1}$ that the radiation width is a function of both the. compound nucleus and channel reactions. The channel reactions, at low energies, preferentially select those states which have a large single-particle character. The $S$-wave neutron is coupled to the core of the target nucleus and undergoes an $E 1$ transition to a low-1ying single-particle p-state without forming a compound nucleus. This effect is strongest for those final states which have strong single-particle components to their wave functions. The channel contribution exhibits resonance energy dependence. The correlations between the partial radiative width and the neutron reduced width are expected for those cases where the $(d, p)$ spectroscopic factors are large. Calculations have been performed in order to understand the correlation observed in the RPI experiments. The initial work examined the channel contributions for the compound nuclei ${ }^{57} \mathrm{Fe}$ and ${ }^{53} \mathrm{Cr}$. These nuclei have strong $(d, p)$ strengths with low-1ying p-states. The information available in stripping, $(n, \gamma),(\gamma, n)$ and gamma-ray spectra for thermal and resonant neutrons was examined. The photoneutron cross sections for ${ }^{57} \mathrm{Fe}$ and ${ }^{53} \mathrm{Cr}$ were measured by Baglan. ${ }^{2}$ The non-resonant capture cross section was obtained by fitting the asymmetric resonant shape for ${ }^{57} \mathrm{Fe}$. The partial radiative widths to the ground

* Based in part on the Ph.D. Thes is of M. Lubert. 
state were obtained from an area analysis. The ratio of these two cross sections was evaluated for the $\frac{1}{2}+$ states assuming that the total contribution for the ground state was due to the channe1 part. The results of these calculations indicate that the correlation exists between the calculated and measured partial radiative width when both are large. The level-level interference modified the area under the resonances substantially so that a multilevel analysis was necessary for the ${ }^{53} \mathrm{Cr}$. The resulting $(\mathrm{n}, \gamma)$ cross section obtained using detailed balance was $0.53 \mathrm{~b}$. This is in good agreement with the experimental value of 0.46 , assuming a branching ratio to the ground state of 0.5 .

\section{REFERENCE :}

1. A. M. Lane, J. E. Lynn, Nuc1. Phys., 17, 563 (1960).

2. R. J. Baglan, UCRL-50902, University of California Radiation Laboratory at Livermore. 
KEV NEUTRON ELASTIC SCATTERING CROSS SECTION IN IRON R. Zuhr, ${ }^{*} \mathrm{Z}$. Bell and K. Min

The following is an abstract of a paper which has been submitted for presentation at the Washington Meeting of the American Physical Society, January 1972.

\begin{abstract}
Neutrons from the RPI LINAC were used to measure the differential elastic scattering cross section of natural iron in the energy region from 10 to $500 \mathrm{keV}$. Scattering was measured at six angles, using a ${ }^{6} \mathrm{Li}$ glass scintillation detector. Energy was determined to an accuracy of 3 nsec per meter by time-of-flight methods, using an on-1ine PDP-7 computer. The angular distributions thus obtained were least-square fitted with Legendre polynomial curves. The resulting Legendre coefficients are given as a function of energy. Total elastic scattering cross sections averaged over an energy interval of $100 \mathrm{keV}$ are presented for comparison with previous results, ${ }^{1}$ and with evaluated total cross sections. 2
\end{abstract}

REFERENCES :

1. A. Langsdorf, R: 0. Lane and J. E. Monahan, Phys. Rev., 107, 1077 (1957).

2. ENDF/B-2, Mat. 1122.

* Based in part on the Ph.D. Thesis of R. Zuhr. 
AVERAGE NEUTRON TRANSMISSION AND SELF-INDICATION RATIO MEASUREMENTS FOR DEPLETED URANIUM IN THE UNRESOLVED RESONANCE REGION* T. Y. Byoun ${ }^{\star \star}$ and R. C. Block

The room-temperature average transmission and self-indication ratio measurements upon various thicknesses $(0.00758,0.01552$, $0.03155,0.04670$ and 0.06206 atom/barn) of depleted uranium have been completed. The cold-to-room temperature measurements of the average transmission and the self-indication ratio have been carried out with two uranium sample thicknesses, 0.03155 and 0.06206 atom/barn, to investigate the Doppler effects. The liquidnitrogen cryostat with an automatic sample changing system has been used to cool samples down to $77^{\circ} \mathrm{K}$. The overall experimental conditions are shown in Table 1.

The room-temperature data have been analyzed in terms of the effective average cross sections ${ }^{l}$ to show the self-shielding effect directly with various uranium sample thicknesses (Figs. 1 and $2)$. The temperature-dependent data have been reduced to cold-toroom ratios of the average transmissions and of the self-indication ratios (Figs. 3 and 4 ). The data have been averaged in energy bins with a width equivalent to $10 \%$ of the central energy point. The thermal expansion of samples, which causes approximately a $0.4 \%$ density change between room temperature and $77^{\circ} \mathrm{K}$ (liquid nitrogen temperature), has not been considered in Figs. 3 and 4.

The statistical accuracy of the data is approximately $1 \%$ in the average transmission measurements and $2 \%$ in the self-indication ratio measurements. Typical experimental results in the neutron energy range from $3.06 \mathrm{keV}$ to $3.38 \mathrm{keV}$ are shown in Tables 2 and 3 .

The cold-to-room ratios of the average transmission and the cold-to-room ratios of the self-indication ratios are plotted in Figs. 3 and 4 for sample thicknesses of 0.03155 and 0.06206 atom/ barn respectively. The observed cold-to-room ratios of the average

* Supported by NASA Grant NGR 33-018-134.

** Based in part on the Ph.D. Thesis of T. Y. Byoun. 
transmission (Figs. 3a, 4a) show mostly $1.5-2.0 \%$ changes in transmission due to the thermal effects. The cold-to-room transmission ratio increases as neutron energy decreases to $3 \mathrm{keV}$ for both samples. For the thick sample below $1 \mathrm{keV}$ the ratio decreases as the neutron energy decreases. The different energy dependency of the cold-to-room transmission ratio in the low energy region appears to be due to the so-called "saturation effects of transmission", which occur when the resonance cross sections or the sample thickness are large enough to black out the neutron flux at the peaks of resonances. This "saturation effect" gives no temperature change of transmission at the peak of a resonance so that the only contribution to the cold-to-room transmission ratio is from the resonance wings. Since the thin sample has less of a "saturation effect", the thin-sample ratio is shown to be higher than the thick-sample ratio in the low energy region. (However, this intuitive explanation cannot be convincing without thorough investigation of the resonance structure.)

The cold-to-room ratios of the self-indication ratios in Figs. $3 \mathrm{~b}$ and $4 \mathrm{~b}$ give rather interesting results. The ratios are slightly less than unity above $7 \mathrm{keV}$. Below $5 \mathrm{keV}$, these ratios increase rapidly to $\sim 1.25$ as the neutron energy decreases to $100 \mathrm{eV}$. At the higher energies, resonances are highly overlapped and the fluctuations in the total cross section become smaller. The shielding samples used ( 0.03155 and 0.06206 atom/barn) are not thick enough to black out the neutron flux in this energy region. Thus, at the peak of a resonance, the self-indication sample will see less neutrons with the cold-shielding sample than with the roomtemperature sample; this will cause the cold-to-room ratio of the self-indication ratio to be less than unity. At the wings of a resonance, this effect is reversed and will yield a ratio larger than unity. Since the self-indication sample has a much larger capture cross section at the peak of resonance, much larger weighting factors must be applied to the resonance peak ratios than to the resonance wing ratios. Therefore, the resonance peak cold-toroom self-indication ratio $(<1)$ dominates in the self-indication 
ratio averaging process. This explains qualitatively why the ratio is less than unity in the high energy region.

At lower energies the shielding sample is so black at resonance that for all practical purposes the self-indication sample does not produce any capture counts near the peaks of the resonances. Thus, the main capture counts take place in the wings of the resonances. The only effect of varying the temperature of the shielding sample is to change the number of neutrons which pass through the wings of the resonances. This leads to fewer transmitted neutrons for the hotter shielding sample, and hence a larger-than-unity cold-to-room self-indication ratio.

The hot-to-room temperature measurements are being carried out. The argon flowing system designed to protect the oxidization of the sample at high temperature $\left(1000^{\circ} \mathrm{K}\right)$, has been replaced with a high vacuum system.

\section{REFERENCE :}

1. Linear Accelerator Project Progress Report, January - March 1970, $\bar{R} P I-328-187$.

\section{FIGURE CAPTIONS}

Fig. 1 The Average Effective Cross Section of Depleted Uranium Calculated from the Average Transmission for 5 Sample Thicknesses $(0.00758,0.01552,0.03155,0.04670$ and 0.06206 atom/barn).

Fig. 2 The Average Effective Cross Section of Depleted Uranium Calculated from the Self-Indication Ratio for 5 Sample Thicknesses $(0.00758,0.01552,0.03155,0.04670$ and 0.06206 atom/barn).

Fig. 3 The Cold-to-Room Ratio of the (a) Average Transmission and of the (b) Self-Indication Ratio for the Sample Thickness of 0.03155 atom/barn.

Fig. 4 The Cold-to-Room Ratio of the (a) Average Transmission and of the (b) Self-Indication Ratio for the Sample Thickness of 0.06206 atom/barn. 


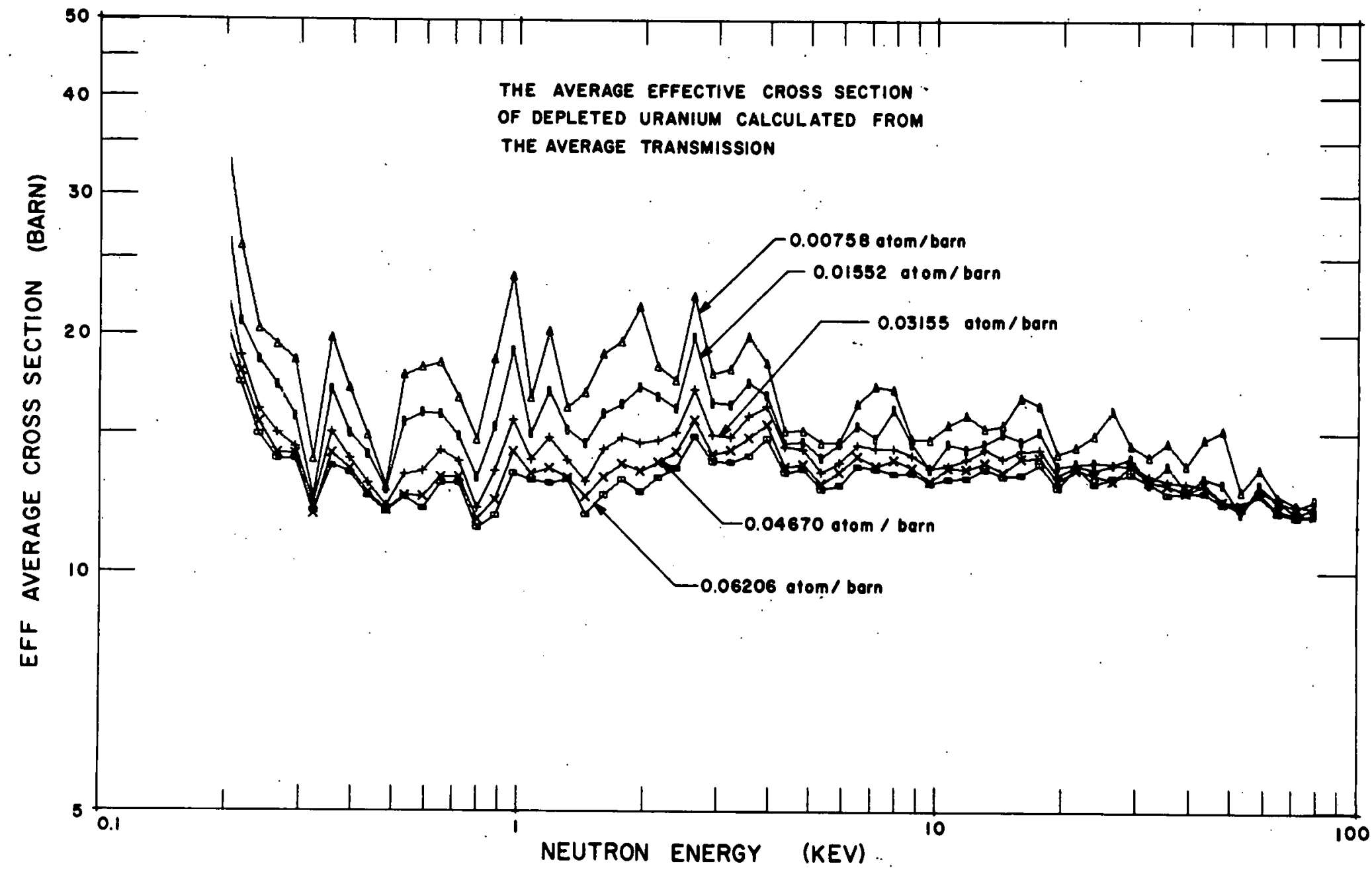

Figure 1 


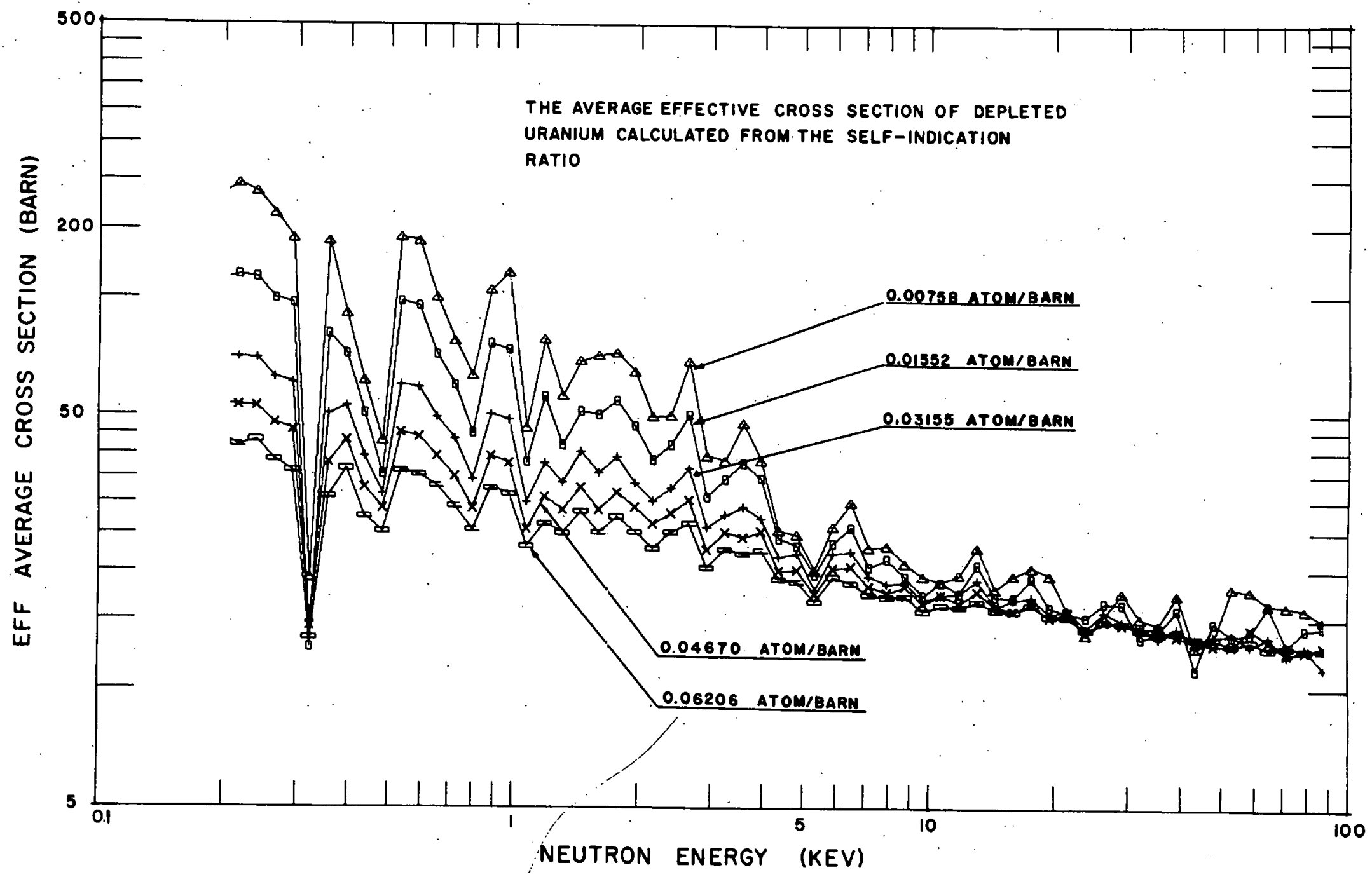

Figure 2 


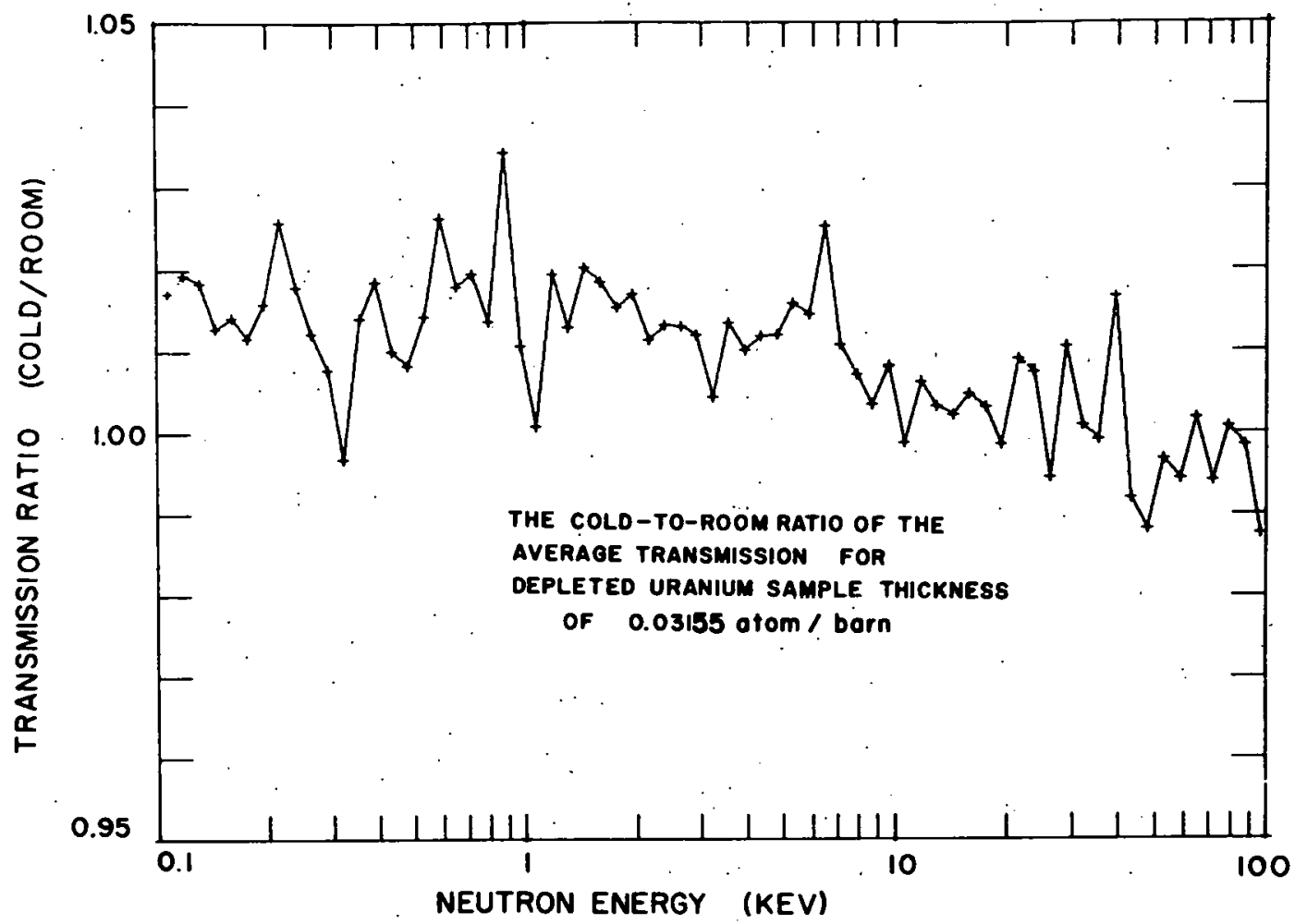

(a)

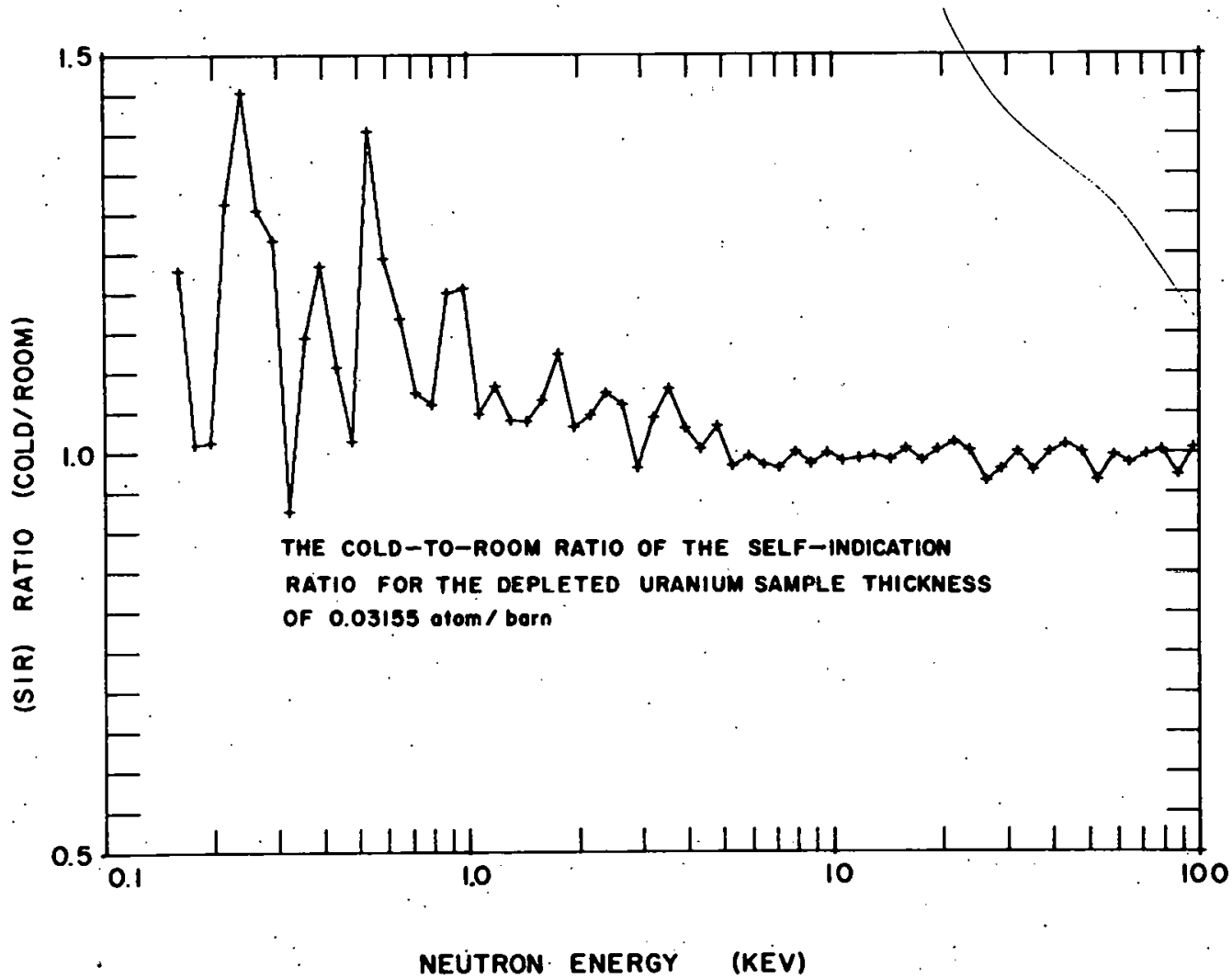

(b)

Figure 3 


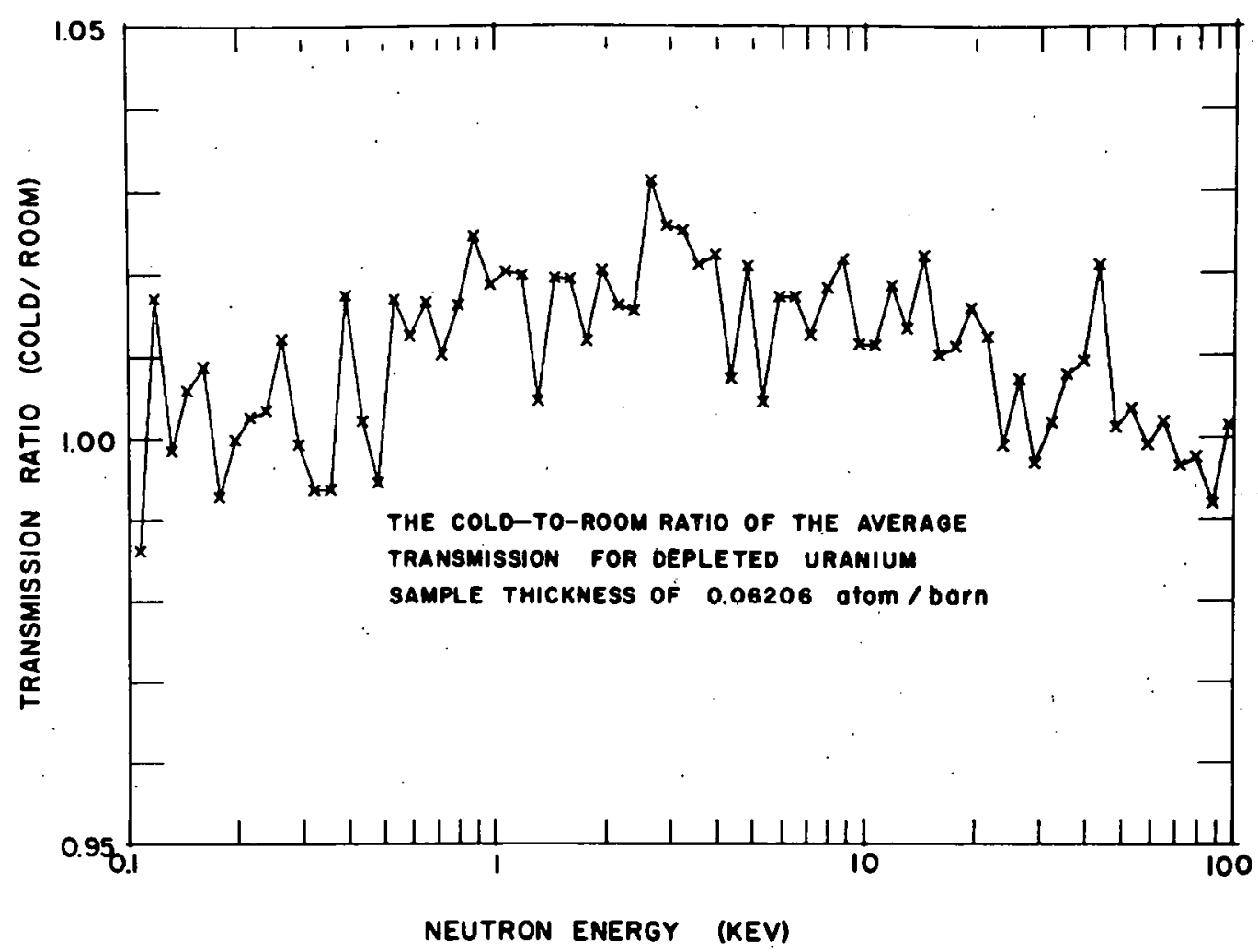

(a)

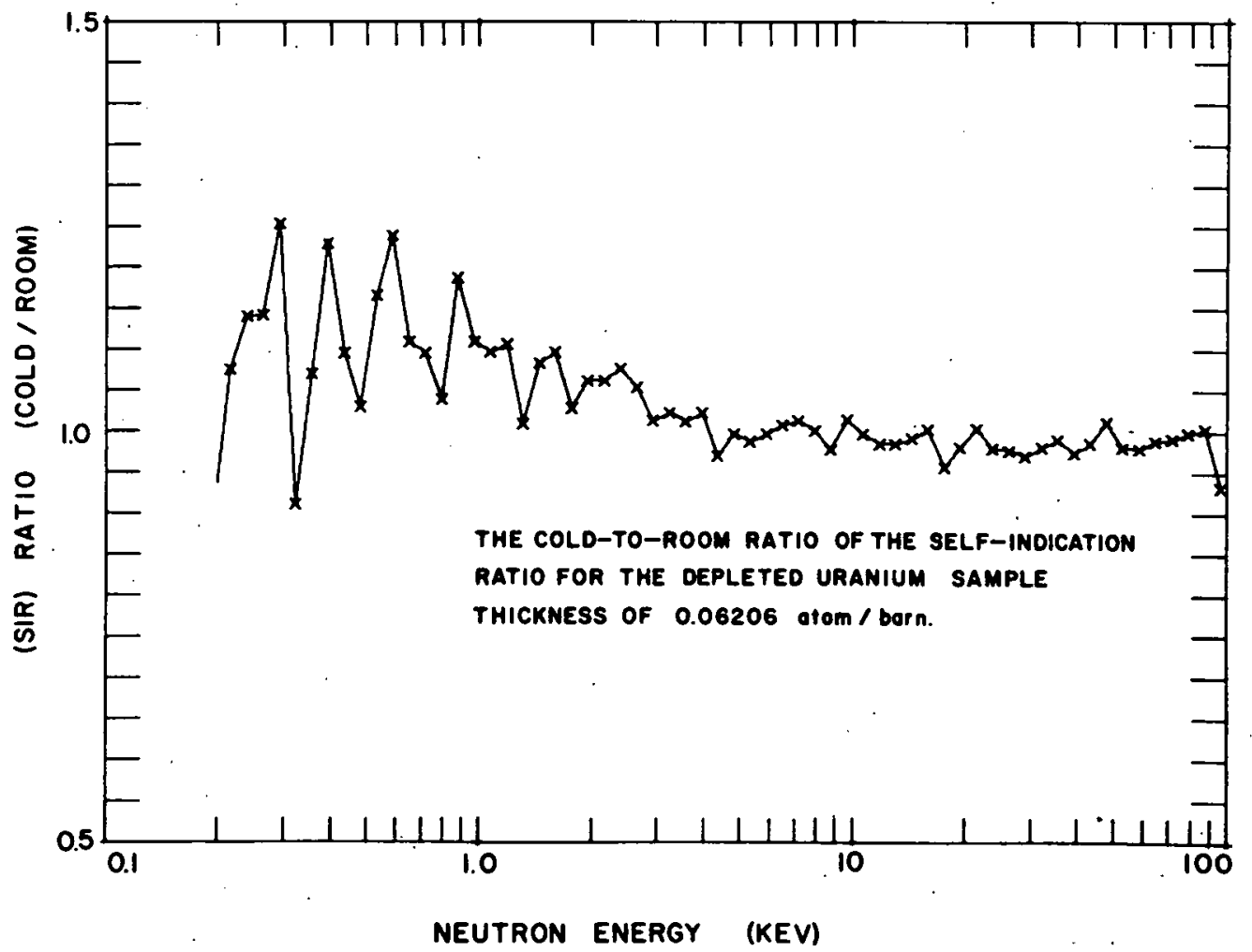

(b)

Figure 4 
Table 1. The Experimental Conditions

Linac Electron Burst Width $\left(10^{-9} \mathrm{sec}\right)$

Electron Energy

Target Average Current ( $\mu$ amp)

Detector

Flight. Path

(meters)

Shielding Samples (atom/barn)

elf-Indication

Sample (atom/barn)

Notch Filters

Shielding Sample

Temperature $\left({ }^{\mathrm{O}} \mathrm{K}\right)$
Room Temperature

Self-Indication Ratio

100

Cold-to-Room

Transmission

50

20

$42 \sim 50$

$50,-60$

$\sim 10.5$

$\sim 65$

$\mathrm{B}^{10}-\mathrm{NaI}$

Tank

28.27

25.69

0.00758

0.01552

0.03155

0.04670

0.06206

$--$

$\mathrm{S}, \mathrm{Al}, \mathrm{Mn}-\mathrm{Cu}$, Co

294

$60 \sim 65$

$-35$

$\mathrm{B}^{10}-\mathrm{NaI}$

28.27

0.01552

0.06206

0.01552

0.03155

0.04670

0.06206

0.00380

$\mathrm{S}, \mathrm{Al}, \mathrm{Mn}-\mathrm{Cu}, \mathrm{Co}$

294

77 and 294
Cold-to-Room Self-Indication Ratio

250

$50 r .70$

$\sim 200$

Tank

25.69

0.01552

0.00380

$\mathrm{S}, \mathrm{A} 1, \mathrm{Mn}-\mathrm{Cu}, \mathrm{Co}$

$\mathrm{S}, \mathrm{Al}, \mathrm{Mn}-\mathrm{Cu}$, $\mathrm{Co}$ 
Table 2. Typical Room-Temperature Experimental Results in the Ennergy Range from $30.06 \mathrm{keV}$ to $3.38 \mathrm{keV}$

Sample Thicknesses (atom/barn)
0.00758
0.01552
0.03155
0.04670
0.06206

Averaze Effective

Cross Section

Calculated from

Transmission

Transmission

$0.872 \pm 0.005$

$0.777 \pm 0.005$

$0.628 \pm 0.004$

$0.515 \pm 0.003$

$0.426 \pm 0.003$ (barns)

$$
\begin{aligned}
& 18.0 \pm 0.8 \\
& 16.2 \pm 0.4 \\
& 14.8 \pm 0.2 \\
& 14.2 \pm 0.1 \\
& 13.7 \pm 0.1
\end{aligned}
$$

Average Effective Cross Section Calculated from

Self-Indication Ratio

$$
\begin{aligned}
& 0.749 \pm 0.007 \\
& 0.588 \pm 0.006 \\
& 0.417 \pm 0.004 \\
& 0.311 \pm 0.003 \\
& 0.246 \pm 0.003
\end{aligned}
$$

Self-Indication Ratio (barns)

$38.1 \pm 1.2$

$34.2 \pm 0.6$

$27.7 \pm 0.3$

$25.0 \pm 0.2$

$22.6 \pm 0.2$

Table 3. Typical Cold-to-Room Temperature Results in the Energy Range from $3.06 \mathrm{keV}$ to $3.38 \mathrm{keV}$

Sample Thicknesses (atom/barn)
0.03155
0.06206

Cold-to-Room Ratio of Average Transmission

$1.005 \pm 0.007$

$1.025 \pm 0.006$
Cold-to-Room Ratio of Self-Indication Ratio

$$
\begin{aligned}
& 1.04 \pm 0.01 \\
& 1.02 \pm 0.01
\end{aligned}
$$


REACTOR PHYSICS AND ENGINEERING - EXPERIMENTAL 
ANALYSIS OF FAST NEUTRON SPECTRA IN BULK MEDIA AND EVALUATION OF DATA FILES E. R. Gaerttner, M. W. Golay, ${ }_{\text {and A. N. Nalien }}^{\text {N. Kaushal, B. K. Malaviya }}$

Analysis and interpretation of fast neutron spectra measured previously is continuing. Results of our analysis of measurements on an iron assembly have been reported in a journal publication. ${ }^{1}$ A similar report on our studies on a uranium assembly has also been prepared for publication. ${ }^{2}$ Analysis of our data on the aluminum assembly is in the final stages and will be reported shortly.

We expect to extend the analysis of these data into $\mathrm{MeV}$ range as the calculational capability for handling anisotropy in cross sections becomes available. We also expect to continue to perform integral checks on later versions of data files (as they become available) for materials for which we have experimentally measured spectrum data.

\section{REFERENCES :}

1. B. K. Malaviya, N. N. Kaushal, M. Becker, E. T. Burns, A. Ginsberg and E. R. Gaerttner, "Experimental and Analytical Studies of Fast Neutron Transport in Iron," to be published in Nuc1. Sci. Eng. (March 1972).

2. N. N. Kaushal, B. K. Malaviya, M. Becker, E. T. Burns and E. R. Gaerttner, 'Measurement and Analysis of Fast Neutron Spectra in Depleted Uranium," to be published (1972).

* Present address: Department of Nuclear Engineering, MIT. 
FAST NEUTRON TRANSPORT IN SODIUM - MEASUREMENT AND ANALYSIS

N. N. Kausha1, B. K. Malaviya, A. N. Mallen and E. R. Gaerttner

Preliminary measurements of fast neutron spectra in sodium were continued during the past quarter. Particular attention is being paid to improving the data in the energy range between $1 \mathrm{keV}$ and $10 \mathrm{keV}$. This involves refinement of the data taken with the existing experimental arrangement and improvement of the experimental arrangement such as designing a new neutron target with larger neutron yield in the low energy region.

An air-cooled welded-construction titanium window has been designed and is being fabricated. When installed, it is expected to improve the ratio between total beam current incident on the target and the current intercepted by the electron beam stripper. This should result in an improvement in the data collection rate. A parallel effort on the calculation of neutron spectra in sodium is also being initiated. 
FAST NEUTRON SPECTRA IN TWO-REGION SYSTEMS

D. C. Gibbs, * B. K. Malaviya, N. N. Kaushal and E. R. Gaerttner

In earlier reports ${ }^{1,2}$ we have described the time-of-flight measurements of position- and angle-dependent fast neutron spectra in a large, two-region aluminum-iron assembly and discussed features of the variation of the spectrum in the vicinity of the Al-Fe interface. Here we report on some aspects of the analysis of these preliminary measurements.

Since for the geometry ${ }^{1}$ of the experiment, the point source and planar media-interface require two-dimensional analysis, the $\mathrm{S}_{\mathrm{N}}$ code DOT-IIW ${ }^{3}$ has been used; the calculations employed 4collapsed energy groups, $\mathrm{S}_{4}$ quadrature and $\mathrm{P}_{3}$ cross sections, derived from ENDF/B-I data. For regions far from the interface, the course anisotropic group constants were weighted by an $\mathrm{MC}^{2}$ generated scalar flux for the $P_{0}$ constants; a sequential iterated transport approximation was used to generate spectral moments for the anisotropic matrix elements. ${ }^{4}$ For regions near the media interface, space-dependent anisotropic coarse-group cross sections were obtained by weighting fine-group cross sections with the flux moments from a one-dimensional $\mathrm{S}_{\mathrm{N}}$ calculation performed in slab geometry with a plane source at a distance equal to the perpendicular distance from the experimental source to the interface. A firstcollision source was used to mitigate the ray effects.

A typical comparison between such an $\mathrm{S}_{\mathrm{N}}$ calculation and the experimental result is shown in Fig. 1. For this figure, the experimental spectra were "collapsed" to the same group structure as that used in the calculation. In a separate comparison, the twodimensional calculations compared well with the results of onedimensional computation, performed in spherical geometry which preserved the perpendicular distance from source to the interface. Much of the discrepancy between the two-dimensional $\mathrm{S}_{\mathrm{N}}$ calculations and experimental results (Fig. 1) can be attributed to the inade-

* Based in part on the Ph.D. Thesis of D. C. Gibbs. 
quacy of 4-group calculations to properly represent spectra in the vicinity of the interface. These results also support the suggestion from another single-region experiment ${ }^{5}$ that the inelastic cross sections of aluminum in ENDF/B-I have been overestimated over all energies and that the aluminum elastic cross sections have not been adequately resolved in the energy range $700 \mathrm{keV}-3 \mathrm{MeV}$.

\section{REFERENCES :}

1. Linear Accelerator Project Progress Report, April - June 1971, 56, RPI-328-226.

2. D. C. Gibbs, B. K. Malaviya, N. N. Kaushal and E. R. Gaerttner, "Studies of Fast-Neutron Spectra Across a Material Interface," Trans. Am. Nucl. Soc., 14, 383 (1971).

3. F. G. Saltesz and R. K. Disney, "Users' Manual for the DOT II W Discrete Ordinates Computer Code," WANL-TME-1982 (1969).

4. A. Ginsberg and M. Becker, "Models for Anisotropic Weighting Spectra," Trans. Am. Nucl. Soc., 14, 368 (1971).

5. M. W. Golay, N. N. Kaushal, B. K. Malaviya, D. C. Gibbs, "Fast-Neutron Spectra in Aluminum," Trans. Am. Nucl. Soc., 14, 836 (1971). 


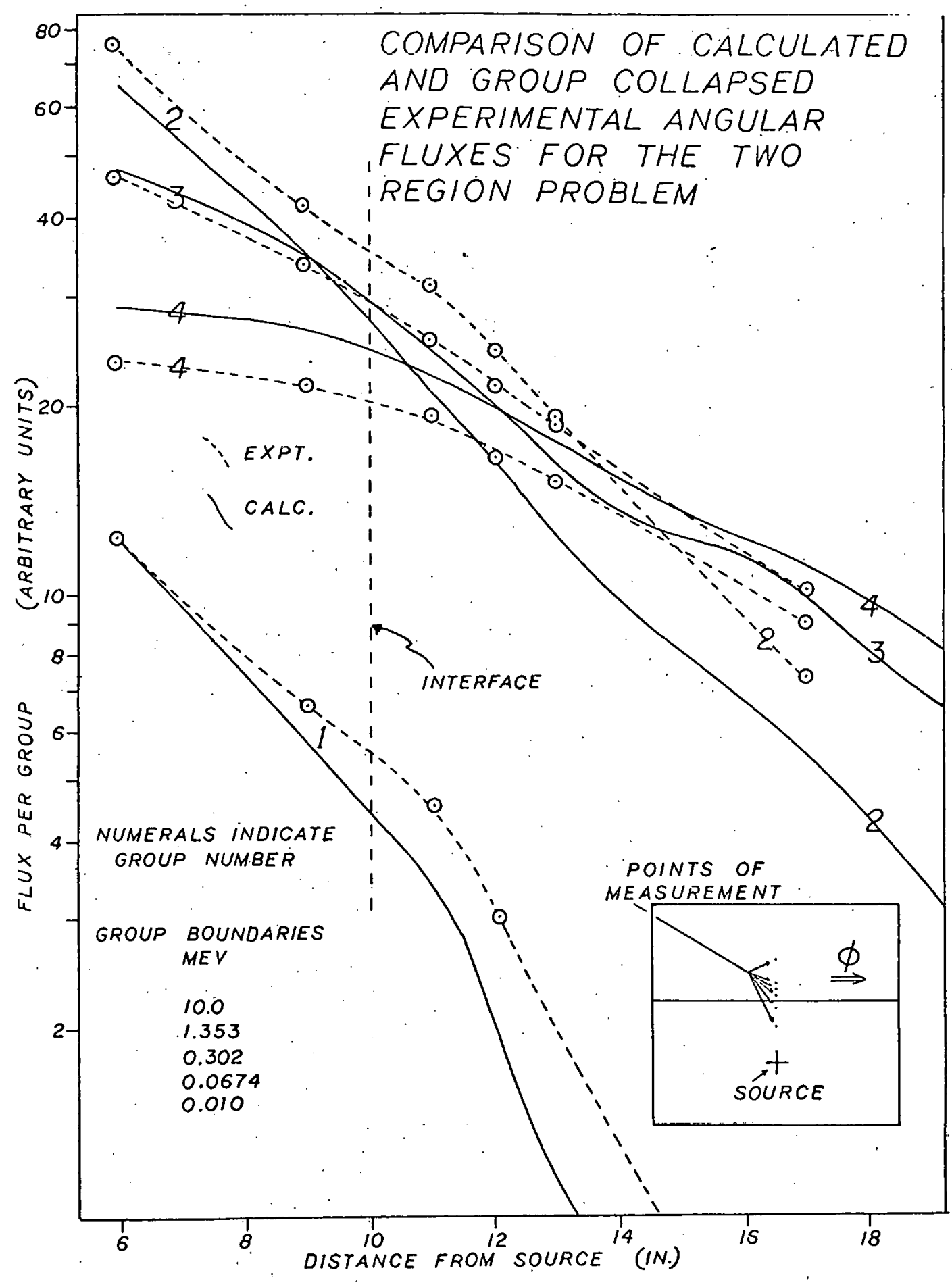

Figure 1 
REACTOR PHYSICS AND ENGINEERING - THEORETICAL 
REACTOR THEORY AND ANALYSIS

M. Becker, G. Epstein, ${ }^{*}$ A. Ginsberg ${ }^{*}$ and S. Kang ${ }^{*}$

Calculations are proceeding using both ENDF/B-I and ENDF/B-II data with high-order anisotropic scattering represented via the RPI version of SUPERTOG. ${ }^{1}$ While it is too early to provide evaluations of high-energy data in the various materials, we can cite one preliminary observation. Comparisons with experiment tend to yield most favorable spectral shapes in "forward" directions, with disparities tending to increase with increasing angle with the forward direction. This may indicate that "forward-peaked" scattering cross sections are given more reliably in the forward direction than in other directions. It still is too soon, however, to advocate a specific conclusion on this matter.

In our Annual Report we discussed our approach to timedependent slowing-down and diffusion. ${ }^{2}$ At that time we indicated that our approach worked reliably for about thirty groups but had numerical disagreement with the time-dependent discrete-ordinate code TDA beyond that group. Further study has shown that TDA calculations were in error for the higher groups, not our approach. To test this conclusion, we integrated the time-dependent solutions for an infinite-medium problem in iron over time and compared the result with a static DTF-IV calculation. The TDA calculations deviated significantly for the higher groups, while our approach was in excellent agreement for the full forty-nine group calculation.

The TDA results deviated significantly from the true solution in two types of situations. One was the presence of a strong resonance. The TDA results did not appear to be capable of predicting the time-behavior of the flux when the cross section varied strongly with energy. This was the type of situation cited above for low energies (high group number). Our approach had no difficulty in the presence of any resonance observed in the energy range studied (10 keV-10 MeV).

* Based in part on the Ph.D. Theses of G. Epstein, A. Ginsberg and S. Kang. 
The second type of situation was at high energies with associated fast time response. Our analytical approach is well-suited to this situation, and is quite accurate. TDA, though, has significant errors. These errors appear to be caused by the size of the time step. Extrapolating from a modest change in time step, it would appear that reduction of time steps to eliminate the error cited would lead to a severe economic penalty to the overall calculation.

It should be noted that while our method is applicable at this stage to specialized situations, it is a very fast calculation, A forty-nine group infinite-medium time-dependent slowing down problem takes on the order of a few seconds on the CDC-6600.

Testing of our interface model has indicated that the model was providing reasonable information on the influence of the interface on the spatial dependence of the gross shape of the spectrum. However, the model was not as effective in treating transitions in fine structure in the immediate vicinity of the interface. These transitions can be complex; for example, the fine structure in the vicinity of the interface need not be intermediate between the fine structures of the asymptotic regions. Slowing-down dependent phenomena such as "reflector peaking" can complicate the situation.

We have formulated an approach to dealing with the fine structure. This approach is based on a heterogeneous few-region collision probability model in the immediate vicinity of the interface. Continuous slowing down theory, including the effects of inelastic scattering, and based on the separable kernel analogy is used. The same general type of equation is obtained as in the single medium model except in matrix form. For example, one equation is

$$
\gamma \frac{d q}{d u}+q=\xi F_{s}
$$

where the slowing down density and scattering collision density vectors are

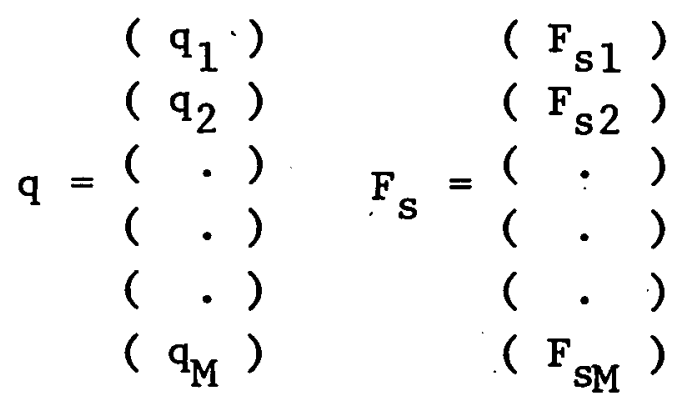


with the subscript being a zone index, and where $\xi$ and $\gamma$ are matrices depending on both the separable kernel properties and on the collision probabilities. We thus expect this model to have analytical and computational advantages analogous to those of our single medium models. This model also should be directly applicable to fast reactor analysis.

\section{REFERENCES :}

1. R. Q. Wright et a1., ORNL-TM-2679, Oak Ridge Nationa1 Laboratory (1969).

2. Linear Accelerator Project Annual Technical Report, October 1, 1970 - September 30; 1971, 137, C00-3058-1. 


\section{CALCULATION OF EXPERIMENTAL RESOLUTION FUNCTION}

\section{K. Alfieri* and P. J. Turinsky}

In neutron cross-section measurements, one must convert counts recorded into cross-section information. For transmission experiments employing time-of-flight ( $T \emptyset F$ ) energy discrimination as performed at this laboratory, the total cross section at energy $E^{\prime}, \Sigma_{t}\left(E^{\prime}\right)$, is related to the counts recorded in the $n$-th $T \emptyset F$ channel, $C_{n}(d)$, through the resolution function, $R_{n}\left(E^{\prime}\right)$, by

$$
C_{n}(d)=\int_{0}^{\infty} R_{n}\left(E^{\prime}\right) e^{-\Sigma_{t}\left(E^{\prime}\right) d} d E^{\prime}
$$

for a sample of thickness $d$. Hence to determine the total cross section from the counts recorded, one must know the resolution function.

Upon making several assumptions which are felt justifiable for our experimental setup, the resolution function is given by

$$
R_{n}\left(E^{\prime}\right)=\epsilon_{\varepsilon}\left(E^{\prime}\right) R_{n}^{o}\left(E^{\prime}\right)
$$

with the ideal normalized resolution function, $R_{n}^{o}\left(E^{\prime}\right)$, defined by

$$
R_{n}^{\circ}\left(E^{\prime}\right)=\int_{t_{n}}^{t_{n}+\Delta t}<L_{T}\left(E^{\prime}, t^{\prime}-\frac{x}{v^{\prime}}\right)>d t^{\prime}
$$

where

$$
\begin{aligned}
& \varepsilon\left(E^{\prime}\right) \ldots \text { slowly varying function of energy } E^{\prime} \text { (velocity } V^{\prime} \text { ) } \\
& \text { related to neutron detector efficiency and source } \\
& \text { intensity, } \\
& t_{n} \quad \ldots \text { time } n-t h T \emptyset F \text { channel opens, } \\
& \Delta t \quad \ldots \text { channel width, } \\
& \mathrm{X} \quad \ldots \text { flight path length, } \\
& <\mathrm{L}_{t}>\ldots \text { total leakage spectra function }{ }^{\mathrm{l}} \text {. }
\end{aligned}
$$

By analyzing data via ratios of counts for two different sample thicknesses, $\epsilon\left(E^{\prime}\right)$ can be eliminated with little error and an analysis conducted for $\Sigma_{t}\left(E^{\prime}\right)$ if $R_{n}^{o}\left(E^{\prime}\right)$ is known.

\footnotetext{
${ }^{*}$ Based in part on the Master's Engineering Project of $\mathrm{K}$. Alfieri.
} 
Employing the results for $\left\langle L_{t}\right\rangle$ reported previously, ${ }^{l} R_{n}^{o}\left(E^{\prime}\right)$ was efficiently computed on the NYU CDC-6600. Defining $E_{n}$ to be the energy at which $R_{n}^{O}\left(E^{\prime}\right)$ peaks, in Fig. 1 are presented calculational results using the experimental conditions of our $\mathrm{Fe}$ measurements. 2 Work is now in progress to imbed these results in an iterative linearized least squares fitting procedure to evaluate total cross sections.

REFERENCES:

1. Linear Accelerator Project Annual Technical Report, October 1, 1970 - September 30, 1971, 144, CO0-3058-1.

2. Linear Accelerator Project Annual Technical Report, October 1, 1970 - September 30, 1971, 19, Co0-3058-1.

Fig. 1 Calculated Ideal Normalized Resolution Function Employing $\Delta t=1 / 32 \mu \mathrm{sec}, X=27.89 \mathrm{~m}$ and Electron Pulse Width $=50$ nsec. 


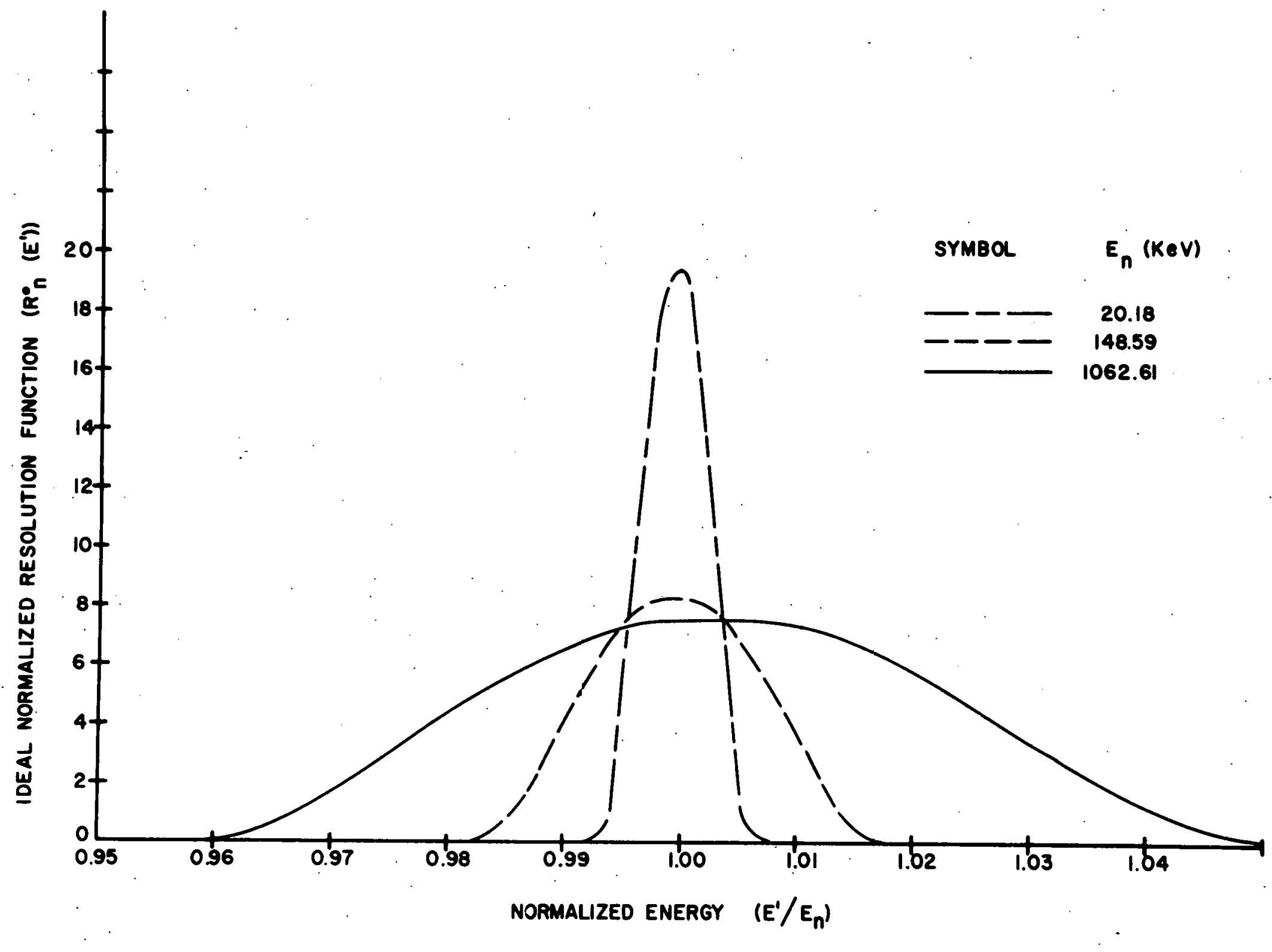

$\stackrel{+}{\infty}$

Figure 1 
FOUR YEARS OF - REMOTE BATCH OPERATION FROM THE RENSSELAER LINAC TO THE COURANT INSTITUTE CDC-6600

\section{W. R. Moyer}

The Rensselaer LINAC remote batch terminal to the Courant Institute (N.Y.U.) CDC- 6600 has been in use for over four years at this writing. It is the purpose of this report to review the terminal system developuent and lu make note of technical accomplishmențs since its inception.

Background

During the past decade the character of experimental work at the Rensselaer LINAC has changed dramatically. The multichannel analyzer capable of 1024 channels of pulse height or time-offlight recording has given way to the small on-line computer. Instead of 1024 channels of information being recorded, it is not uncommon today to see several hundred thousand channels being recorded simultaneously. Even though the number of channels recorded per measurement has increased, the great efficiencies effected by the use of automated data acquisition have allowed more measurements per man year -- generating even more experimental data. All these data must be processed in some fashion to extract the desired measurement parameters.

Advances made in our understanding of the physical processes involved in a measurement make even greater demands upon the data processing facility. Not only do we have more data to process, but we have to do more to process each point.

The combined effect of greater experiment complexity, large amounts of data produced and the greater demands of data evaluation is clear. Access to a large, fast computer is absolutely necessary.

Our first on-line data acquisition computer started producing data in 1964. By 1966 we were beginning to feel a real pinch in our data processing capability. The "in-house" IBM 1620 was no longer able to meet the demands of data processing as well as 
theoretical calculations. We contacted the Courant Institute at N.Y.U. about the use of their control Data CDC-6600. The . Courant machine looked very attractive. It had the memory capacity, speed and magnetic tape storage which we needed. We estimated that our entire data processing load for a year (1968), could be handled, using a total of 25 hours if it could be done on the Courant machine. We had the blessings of the AEC and Courant staff to use their facilities. After several months of experience with the Courant machine, it became apparent that the 160 miles which separated us posed an insurmountable hurdle. One obvious problem of using such a distant computer facility is of course the travel time by car or train -- nights' lodging if necessary. Another problem is the turn-around time; i.e., the span of time from problem submission to return of results. Turnaround time in our case was measured in hours, while the typical problem submitted took less than 40 seconds of actual machine time.

Other problems with commuting to a distant facility appeared. It is usually true that the person who writes a processing code is the most familiar with its content and idiosyncrasies. To achieve even the three pass per day level, it must be the author or prime user himself who travels to the computer site; for a messenger would likely not know how to correct the errors in program or input data which frequently occur.

A final, and possibly most serious flaw in travelling some distance to a computer center is the separation between the point of problem submission and the researcher's primary data, records and familiar references. Frequently a computer result will raise a question which can only be answered by reference to notes "back at the lab." This situation usually results in a colossal waste of time.

Discussion with the Courant staff led to our interest in the possibilities of a remote terminal system capable of operating in batch mode into the CDC- 6600 . 
Remote Batch

The difference between a "remote batch" terminal and a "time sharing" terminal should be made clear at this point. Time sharing is usually carried out with operator-machine interaction via a teletype terminal or equivalent. Interaction is usually conversational with the operator supplying abbreviated commands and input data while receiving output information in real time.

A remote batch terminal as far as the operator is concerned is functionally identical to the main system card reader and line printer. Jobs are loaded complete with system command instructions, programs, data, etc. as an integral input file. After the entire job is processed, output is available in the form requested by input commands. No attempt is made to interact in "real time." The remote batch form of operation was decided upon.

Communication Link

Establishing the form and mode of communication required the close cooperation of both ends of the proposed link. Based upon speed requirement and initial cost among other factors, a single voice grade private line leased through G.S.A. was to be used from Manhattan Island to Albany, New York. The system was to be "dialup" so that we could telephone other datasets if we should desire, and so that the dataset at courant could be dialed by other users. The maximum speed dataset supplied by the Telephone Company for this type of line is the $201 \mathrm{~A}$ series datasets clocking synchronously at 2000 baud (bits/second). Courant selected a 201A3 dataset with internal clocking. Any equipment which we would select would have to be compatible with this dataset.

\section{Hardware}

A market survey was initiated to see what equipment could be used as a remote batch terminal. Among factors used as a selection guide, the following were prime:

(a) The system should be compatible with the Western Electric 201A3 type datasets.

(b) The entire system should be commercially available so that the system could be easily duplicated by other users. 
(c) The terminal should be as versatile as possible to take advantage of communications software developments at Courant.

Two possible approaches were seen. One was that of a hardwired or fixed program terminal; the other a general purpose computer with communications capability. Each approach has its strengths and weaknesses.

I. Hardwired Terminal

con:

-- handles limited character set

-- fixed record length usually one line or card

-- speed limit about one line or card per second on half duplex

pro:

-- turn-key operation

-- about half the cost of computer approach

-- when not being used as a terminal, it can list or duplicate decks

-- Courant was initiating a program to communicate with a Univac DCT-2000, a hardwired terminal

II. Computer with Communications Capability con:

- greater cost than hardwired terminal

-- extensive communications software development required

pro:

-- character set unlimited

-- binary transmission possible

-- record length not fixed

-- with software, the computer can be made to imitate any hardwired terminal

-- when not being used as a terminal, it can run local jobs in FORTRAN IV for data formating, etc.

-- larger choice of peripherals

The decision was to opt for the more versatile computer system -- the logical candidate being at that time an IBM 1130 with a 
synchronous communications adapter, a card reader/punch, line printer, disk and calcomp type plotter. The particular configuration chosen is given in Appendix A. Software development for the terminal was carried out at the RPI LINAC site with the close cooperation of Courant staff.

History

The system was operable as a computer as soon as it was delivered. Immediately users began to makc use of the data formating (such as paper tape to card conversion) and graphic output capabilities of the IBM 1130. Software development was begun to make the IBM 1130 emulate a Univac DCT-2000 hardwired terminal. The first successful transmission from the IBM 1130 card reader, through the telephone line, through the interface system at Courant ${ }^{*}$, directly into the CDC- 6600 job input queue took place in the fall of 1967. Two-way communication was established in December 1967. Two other AEC contractors with similar IBM 1130 configurations were supplied with the software developed at Rensselaer. No problems were encountered and they were able to communicate with Courant immediately. In return, one contractor (Brandeis) modified the software package to transmit binary records, taking advantage of software improvements effected at Courant. Brandeis transmitted the modified package. to us by telephone via the Courant CDC- 6600 .

Performance

The effect of direct access to the innards of the Courant CDC- 6600 was dramatic. Within months after the link was operational all major computing at the Rensselaer LINAC was being done on the CDC- 6600 via the IBM 1130 terminal. Although there have been many performance improvements at both ends of the telephone

\footnotetext{
* An Interface Between a Control Data 6000 Series Computer and a Honeywell 16-Bit Series Computer," Ronald Bianchini, AEC Computing and Applied Mathematics Center, Courant Institute of Mathematical Sciences, New York University, NY0-1480-119 October 1969.
} 
line, the basic philosophy of the terminal operation has remained unchanged. Current performance specifications are given in Appendix B.

Jobs entered into the terminal go directly into the CDC-6600 operating system queue and are handled just as if they had been entered on-site. The person who submits the job can interrogate the status of his job at any time through simple keyboard commands. Output can be received at the terminal in the form of listings or punched cards. Output may also be directed to any peripheral device at Courant under the control of the operating system. Through the operating system the terminal user can request his tapes to be mounted, his job proceeding from the point of request after the CDC- 6600 operator has mounted the requested reels. Virtually any user program which can be run at the CDC- 6600 site can be run from the remote terminal with much less turn-around time and greater coupling between the user and the 6600 operating system.

Aside from the great benefit of having access to -- but not having to staff or maintain -- a CDC-6600, a number of incidental side benefits to the terminal user are worth noting. Software development is expensive and LINAC data is irreplaceable. Our usual operating procedure is to store primary data and programs on cards or tape at the terminal site. These data are transmitted once to Courant and stored on tape for processing as needed. Thus important information exists in two physically separate locations eliminating the chance of information loss due to physical catastrophe.

A remote terminal user can communicate with other remote installations via the CDC- 6600 independent of the type or speed of terminal at each remote site -- a great opportunity for software sharing.

The remote terminal on a "dial-up" telephone line is not limited to communicating with only one computer center. This is especially true of the more adaptable computer system terminal 
compared with the hardwired terminal. Two experiences show the possibilities. The first occurred when the Courant CDC-6600 was scheduled for an extensive maintenance period. Within a week the Courant staff had interfaced another CDC-6600 somewhere else in Manhattan to the telephone system. By dialing another number it was "business as usual" for us.

As an experiment in versatility of our IBM 1130 terminal, we made arrangements with a commercial computer service outfit to phone into their IBM $360 / 95$ in Canada. In the time it took to place the call, a remote job entry program was loaded into our IBM 1130 and a test problem run on the Canadian machine. Reliability

When considering the reliability of remote batch operation, usually the big unknown is the communications link over which one has little control. In the past twelve months we have lost less than five hours of access time due to telephone problems. Line problems have been easily detectable and have usually been corrected within two hours of notification to the Telephone Company repair service.

Sporadic errors due to impulse noise or short duration bursts are detected by communications software and record re-transmission is initiated. The error rate is low -- less than one error per day. There has been no evidence of any errors which have not been detected and corrected by the communications software.

Summary

Remote batch operation from the Rensselaer LINAC to the Courant Institute CDC- 6600 has been very successful. Probably the greatest tribute to the capability of remote batch processing is the fact that the Courant Institute staff itself uses a remote terminal for in-house processing and operating system development. Any conceivable user program which can be run "on-site" can be run on a remote batch terminal. 


\title{
Appendix A
}

\section{Rensselaer LINAC Remote Batch Terminal}

IBM 1130 Computer consisting of the following components:

1131 Model 2B Central Processor 8K core

1132 printer 120 column

1134 paper tape reader, 50 characters/second

1142 Model 7 card read punch

1627 Model I plotter

7690 synchronous communication adapter

\author{
Appendix B \\ Rensselaer LINAC Remote Batch Terminal \\ to Courant CDC-6600
}

Performance Summary

Dataset type:

Carrier:

Distance:

Mode:

Speed - xmit:

Speed - receive: about 1 line per second

Speed limitation is due to the terminal 1132 printer

A typical FORTRAN listing could be received at 400-500 lines/minute given the appropriate printer.

Speed - punch:

Data modes:

Error rate:

$201 \mathrm{~A} 4$ (2000 baud, half duplex)

dial up - voice grade leased telephone line (G.S.A.)

about 160 miles

binary synchronous communication about 16,000 card columns/minute

A typical FORTRAN program transmits at the card reader limit of $400 \mathrm{cards} / \mathrm{minute}$

Full 80 column data cards run at the worst case speed of about 200 cards/minute

about 2 cards/second

limited by the terminal 1442 punch mechanism any -- since transmission mode is binary. Records assembled in the IBM 1130 terminal prior to transmission are in CDC-6600 - 60 bit internal format

Detectable errors due to telephone link -less than one character/day average. 